Revista lus et Praxis, Año 25, No 1, 2019, pp. 335 - 382

ISSN 0717 - 2877

Universidad de Talca - Facultad de Ciencias Jurídicas y Sociales

Acerca de la responsabilidad civil postcontractual

en el derecho del consumidor chileno

Érika M. Isler Soto

Trabajo recibido el 26 de diciembre de 2017 y aprobado el 12 de noviembre de 2018

\title{
Acerca de la responsabilidad civil postcontractual en el derecho del consumidor chileno*
}

\author{
ABOUT THE POSTCONTRACTUAL LIABILITY IN THE CHILEAN \\ CONSUMER PROTECTION LAW
}

ÉRIKA M. ISLER SOTO**

\section{ResUMEN}

Este documento analiza la responsabilidad postcontractual en sede de protección de los derechos de los consumidores. Se postula que ellos sí proceden, y se derivan de la ley, sea que el legislador la haya mencionado expresamente o que se derive de la buena fe. Corresponde además a responsabilidad de naturaleza contractual.

ABSTRACT

The author analyzes the post-contractual liability in the Consumer Protection law. It is postulated that this liability exists, and it is derived from the law, whether the legislature has expressly mentioned or resulting from good faith. It also corresponds to contractual liability.

Palabras Clave

Consumidor, responsabilidad postcontractual, buena fe

KEY WORDS

Consumer, postcontractual liability, good faith

\section{Introducción}

Además de la responsabilidad civil que surge antes de la celebración del contrato, o con posterioridad a ello (art. 1556 CC), encontramos una tercera etapa de la cual se pueden derivar igualmente deberes para una de las partes. Es la denominada postcontractual y que procede una vez que ya se han extinguido sus obligaciones esenciales.

\footnotetext{
* Proyecto UBO/VRIP170105. Agradezco a la profesora Javiera Farías Soto y a las alumnas María Paz Benavente y Clarissa Herrera, por la proporción de alguna jurisprudencia que sirvió para la elaboración de este artículo.

** Abogada; Licenciada en Ciencias Jurídicas y Sociales, Universidad Austral de Chile; Magíster en Derecho, mención Derecho Privado, Universidad de Chile; Magíster en Ciencia Jurídica, Pontificia Universidad Católica de Chile; Doctora en Derecho, Pontificia Universidad Católica de Chile; Profesora de Derecho Civil, Universidad de Talca; Profesora de Derecho Civil, Universidad Bernardo OHiggins; <erikaisler@yahoo.es>.
} 
Ello también confluye con la apertura a revisarse la teoría del negocio jurídico desde una perspectiva sistémica. Así, como explica Lorenzetti si bien el estudio del contrato en un inicio se parecía a una fotografía estática, el dinamismo del que goza a partir de la extensión del iter contractual con una -en ocasiones- dificultosa división de sus etapas, la ha tornado en una película ${ }^{1}$. En efecto, la observación de los actuales sistemas de contratación ha conllevado el cuestionamiento del efecto relativo de los contratos, de la autonomía de la voluntad como suficiencia de la obligación, así como de las fases en las cuales la convención es relevante. Es en este escenario, entonces, en el cual aparecen dimensiones antes no analizadas y que se relacionan directamente con el objeto de estudio, tales como los deberes que surgen una vez que se ha agotado el contrato, la consideración de la buena fe como elemento integrador y generador de obligaciones, y la formulación de regímenes unitarios de responsabilidad.

Por otra parte, la Ley № 19.496 (LPDC), que contiene la regulación general de las relaciones de consumo, coincidente con su tendencia a reconocer acciones civiles sin regularlas ${ }^{2}$, no se refiere expresamente a la responsabilidad postcontractual. La doctrina asimismo es escasa y alude sólo tangencialmente a ella, de tal manera que no existe literatura conocida que estudie sistemáticamente los deberes que surgen para el proveedor, una vez que se han cumplido las obligaciones principales derivadas de la convención. Asimismo, los pocos pronunciamientos judiciales que existen sobre la materia suelen ser además contradictorios, por lo que tampoco tenemos evidencia de una tendencia jurisprudencial marcada de la cual se pueda extraer una teoría general.

No obstante, esta temática es relevante, desde que el panorama expuesto deja al sujeto débil de la relación de consumo en una situación de desamparo al no existir claridad respecto de los derechos de los que es titular, una vez que el contrato en esencia se ha cumplido. En efecto, en las hipótesis en que se ha planteado directamente esta cuestión, precisamente la defensa de los denunciados suele sustentarse en la extinción de la relación convencional de consumo, la cual ha sido lamentablemente acogida en ocasiones.

El presente documento tiene por objeto proponer los presupuestos de configuración de la acción indemnizatoria derivada de los daños postcontractuales, así como de su régimen jurídico.

\footnotetext{
1 LORENZETtI (sin año), p. 40.

2 Si bien el proyecto de ley Boletín № 9.369 contempla una remisión al Derecho común a propósito de la prescripción extintiva, ello resolvería sólo en esa parte el problema, quedando sin solución el resto de las materias, tales como su carácter objetivo o subjetivo, legitimados activos y pasivos, etc.
} 


\section{Acerca de la responsabilidad postcontractual en general}

\subsection{Concepto}

Como se adelantó, desde el punto de vista cronológico, se pueden distinguir tres etapas en el contrato ${ }^{3}$ : los tratos preliminares, su perfeccionamiento y su cumplimiento, entendiéndose que esta última se produce cuando se ejecutan las prestaciones derivadas del $\mathrm{mismo}^{4}$. En este escenario, Benítez define a la responsabilidad postcontractual como "aquella que acaece como resultado de la violación de un deber de conducta, derivado de la buena fe que se erige como standard jurídico, con posterioridad a la satisfacción de las prestaciones principales de un contrato, produciendo en la otra parte un daño indemnizable" ${ }^{\prime \prime}$.

Por su parte, para Rodríguez Russo, la etapa del postcontrato se produce cuando "las obligaciones principales dimanantes del mismo han sido cumplidas, pero quedan subsistentes determinados deberes de conducta derivados de la buena $\mathrm{fe}^{1{ }^{\prime}}$. Leiva Fernández, en tanto, señala que es aquella "en la que se incurre por alguno de los excocontratantes con posterioridad a la satisfacción de las prestaciones principales de un contrato, sea que se origine en un hecho posterior o anterior a dicha satisfacción" ${ }^{\prime \prime}$.

De esta manera, es posible señalar que el elemento caracterizante de este tipo de responsabilidad, además de la generación de un daño, radica en que aparece una vez que se han extinguido las obligaciones principales del contrato. Así las cosas, lo que se debe examinar para determinar si se configuró o no una hipótesis como la señalada, es el lugar que ocupa dentro del iter contractual.

En España por su parte, Vattier Fuenzalida, a propósito de los deberes derivados de los contratos electrónicos, insinúa que la responsabilidad postcontractual surge una vez que se ha perfeccionado el contrato, mencionando la obligación del proveedor de confirmar su celebración y enviar la información correspondiente al consumidor para que éste la pueda almacenar ${ }^{8}$.

\footnotetext{
${ }^{3}$ Benítez (2013) lo sitúa en el consentimiento, no obstante, se debe atender al criterio del perfeccionamiento, puesto que, si en un contrato no se cumplen ciertos requisitos externos exigidos por el legislador para que se entienda que nace a la vida del derecho, no surgirá responsabilidad postcontractual.

4 Rodríguez (2015), pp. 935 y 936.

${ }^{5}$ Benítez (2013).

${ }^{6}$ Rodríguez (2015), p. 936.

7 Leiva (2002).

${ }^{8}$ VATtier (2001), p. 84.
} 
No obstante, en nuestro sistema el nacimiento de la convención a la vida del derecho implica el surgimiento de las obligaciones también esenciales, por lo que no resulta un criterio adecuado y certero de calificación de la responsabilidad como postcontractual. Por otra parte, la LPDC exige para la forma de contratación señalada que el consumidor haya tenido la posibilidad de conocer y almacenar las condiciones contractuales para que el consentimiento se entienda formado (art. 12 A LPDC), de tal manera que este presupuesto opera en la fase precontractual.

Cabe señalar, asimismo, que la doctrina suele agregar que este tipo de responsabilidad surge a partir del incumplimiento de deberes derivados de la buena fe, por lo que no requieren de mención convencional expresa. Ello es parcialmente correcto, en el sentido de que podrán tener una fuente convencional o normativa, pudiendo encontrarse específicamente contemplados en una disposición legal, o bien desprenderse de la consagración general de la buena fe como mecanismo de integración del contrato. Se volverá sobre esto más adelante.

\subsection{El reconocimiento normativo de la responsabilidad postcontractual}

\subsubsection{El Derecho comparado}

Un eventual reconocimiento expreso normativo lo podríamos haber encontrado en Argentina, si hubiese entrado en vigencia el Proyecto de Código Civil de 1998. En efecto, dicha propuesta señalaba en su art. 1063: "Con ulterioridad al cumplimiento de las obligaciones principales propias del contrato las partes deben continuar actuando de buena fe". Agregaba dicha disposición que el mencionado deber regulaba los siguientes aspectos: “a) La determinación de la existencia y de los alcances de las obligaciones accesorias que subsisten, por estipulación de partes, o por estar virtualmente comprendidas en el contrato. b) La restitución y la reparación de daños, en cuanto correspondan una vez producida la extinción del contrato (...). c) La interpretación y el cumplimiento de tales obligaciones".

No obstante, esta inclusión no prosperó, al considerar finalmente los redactores del Anteproyecto de Código Civil y Comercial que ello era innecesario, por haberse regulado la etapa de ejecución del contrato ${ }^{9}$, en la cual

\footnotetext{
${ }_{9}$ Actualmente el art. 961 CCCo, señala: "Buena fe: Los contratos deben celebrarse, interpretarse y ejecutarse de buena fe. Obligan, no sólo a lo que está formalmente expresado, sino a todas las consecuencias que puedan considerarse comprendidas en ellos, con los alcances en que razonablemente se habría obligado un contratante cuidadoso y previsor".
} 
se entendía comprendida la fase postcontractual ${ }^{10}$. Aunque esta concepción implicó la ausencia de una mención expresa de la responsabilidad objeto de este trabajo, al mismo tiempo, nos otorga luces en orden a considerar que su naturaleza entonces tendría un carácter contractual, puesto que los deberes de los que emanan son parte de la ejecución misma de la convención.

Con todo, esta decisión fue criticada también por parte de la doctrina ${ }^{11}$. Así, por ejemplo estimaba Benítez: "Quizás esto sea así debido a la unificación de las categorías de la responsabilidad civil y en aras a no crear nuevas figuras jurídicas que compliquen la cuestión. No obstante esto, no nos parece que so pretexto de unificación de régimen de responsabilidad civil no se legisle en esta materia"12.

Ahora bien, cuando los deberes postcontractuales no cuentan con una consagración en específico, se los suele desprender de la buena $\mathrm{fe}^{13}$, la cual sí se encuentra mencionada por las legislaciones en términos generales. De lo anterior se puede colegir, que los imperativos postcontractuales no requieren de una mención expresa por las partes, puesto que el legislador ya los ha incorporado al contrato, aun cuando no se tipifiquen individualmente.

Así, por ejemplo, lo ha señalado el mismo Benítez respecto de la legislación argentina, frente a la omisión ya señalada14: "El artículo claro está, no habla de la responsabilidad postcontractual, pero no obstante sí toma partido respecto de la consagración del ensanchamiento de los deberes en los contratos a que hace referencia la doctrina"15.

Algo similar ocurre en Colombia, país en el cual, frente al silencio legislativo, también se ha extraído la vigencia de los deberes colaterales a partir de los imperativos de la buena fe consagrados en el art. $1603 \mathrm{CC}^{16}$, disposición cuya redacción es similar a nuestro art. 1546 CC. La fase postcontractual, asimismo, podría verse alcanzada -tal como lo habían señalado los redactores

\footnotetext{
${ }^{10}$ Fundamentos del Anteproyecto de Código Civil y Comercial de la Nación, disponible en: http://www.lavoz.com.ar/files/FUNDAMENTOS_DEL_ANTEPROYECTO_DE_CODIGO_CIVIL_Y_ COMERCIAL_DE_LA_NACION.pdf, revisado el 21.12.2017, p. 145.

11 Benítez (2013).

12 Benítez (2013).

13 Larenz (1958-1959), p. 154; Le Tourneau (2004), p. 104; Rezzónico (1999), p. 529; RodríGuez (2015), pp. 940 y 941; Vera (2014), p. 82.

${ }^{14}$ Benítez (2013), así lo señala respecto del art. 1198 del CC de la época, aunque lo mismo puede decirse del art. 961 del CCCo. actual.

15 Benítez (2013).

16 Bernal (2013), p. 57.
} 
del Anteproyecto de CCCo argentino-, por la exigencia de que los contratos "deben ejecutarse de buena fe"17.

Lo propio puede sostenerse de España, desde que del art. 1258 CC, algunos autores también han desprendido la procedencia de la responsabilidad postcontractual ${ }^{18}$. Dicha norma prescribe que los contratos obligan tanto en lo que expresamente se ha pactado, como a las consecuencias que, según su naturaleza, sean conformes a la buena fe, al uso y a la ley ${ }^{19}$.

\subsubsection{La situación en Chile}

Nuestro Código Civil no se refiere de manera explícita a la responsabilidad en análisis, lo que no constituye ninguna novedad, si tomamos en consideración la época de su dictación. No obstante, al igual que en los regímenes foráneos, sí se reconoce que los imperativos de la buena fe deben ser satisfechos en la ejecución de los contratos (art. 1546 CC), norma de la cual algunos autores derivan los deberes postcontractuales ${ }^{20}$.

Nuestra jurisprudencia se ha pronunciado en el mismo sentido, estimando que "la buena fe, al ser un principio general del derecho y en especial de la contratación civil, se debe considerar su aplicación en todo el iter contractual, desde la etapa de tratativas preliminares, la celebración del contrato, ejecución del mismo, interpretación contractual e inclusive el período postcontractual" 21 .

También en AGL Comercial Limitada con Corporación Nacional del Cobre de Chile (2014) el tribunal estimó que, aun cuando se habían terminado los contratos que vinculaban a las partes -Manejo de Soluciones Lixiviación, Ripios, Túneles de Recolección y Superficie Minas $\mathrm{DCN}{ }^{22}$, podía proceder responsabilidad: "si bien es un hecho cierto que los contratos terminaron

\footnotetext{
${ }^{17}$ Vemos aquí una diferencia con la redacción del CCCo. argentino, en el sentido de que el primero además hace alusión además a la celebración e interpretación del contrato, con lo que una fundamentación de la responsabilidad precontractual se facilita enormemente.

18 Conde (2007), p. 202; Monsalve (2008), p. 47.

19 Art. 1258 CC, España: "Los contratos se perfeccionan por el mero consentimiento, y desde entonces obligan, no sólo al cumplimiento de lo expresamente pactado, sino también a todas las consecuencias que, según su naturaleza, sean conformes a la buena fe, al uso y a la ley".

20 López (2005), p. 414; Rodrí́Guez (2015), p. 936; Ugarte (2012), p. 712. En materia laboral: IRURETA (2011), pp. 152 y 182.

${ }^{21}$ Corte Suprema, rol № 1872-2010, de 29 de diciembre de 2011.

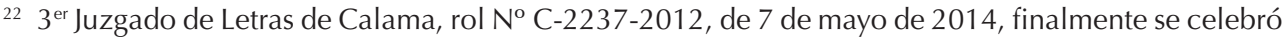
transacción, Corte de Apelaciones de Antofagasta, Ingreso № 626-2014, de 22 de diciembre de 2014.
} 
en el mes de julio de 2007, debe desestimarse esta alegación toda vez que nuestra doctrina ha distinguido el período postcontratual, como aquel que se inicia al satisfacer las obligaciones principales del contrato, por lo que si las obligaciones principales del contrato no se cumplen la responsabilidad será contractual. En autos las alegaciones que hace la actora miran al cumplimiento de las obligaciones contractuales incumplidas, toda vez que reclama, entre otras, prestaciones que se derivan del cumplimiento del contrato, como lucro cesante, obligaciones que son principales". No obstante, se rechazó la acción por encontrarse prescrita.

En Palacios Krogh con Stone Cereceda (2011) en tanto, el máximo Tribunal también estimó que la buena fe contractual se extiende desde la etapa precontractual, hasta la postcontractual, por lo que se debía indemnizar a los actores a quienes no se les habían construido cabalmente los caminos de acceso a unas parcelas anteriormente adquiridas ${ }^{23}$. Cabe señalar que, en este caso, el deber de construcción de vías de acceso no se deriva únicamente de la buena fe, sino que además pudo haber tenido como fuente el contrato, por lo que no tendría el carácter de implícito.

Ello tendrá relevancia en lo que se verá con posterioridad acerca de la propia calificación del cumplimiento y que se evidencia también en la sentencia Inversiones Clarkson y Compañía Limitada con Donoso Caamaño (2014), por la cual la Corte Suprema, aludiendo a la procedencia en Chile de la responsabilidad postcontractual, agregó que la presencia de defectos en la construcción implicaba el incumplimiento de las obligaciones contractuales ${ }^{24}$.

También en Fritz Vidal con Banco Santander Chile (2011) el mismo Tribunal -aunque con dos votos de minoría ${ }^{25}$ reconoció deberes de este tipo, al condenar a un Banco al pago de \$5.000.000 como indemnización del daño moral producido a un individuo, cuya deuda había sido informada a la Superintendencia de Bancos e Instituciones Financieras (SBIF), aunque constaba en un pagaré largamente vencido. En este caso, se invocó como fuente del resarcimiento la vulneración del art. 1546 CC (buena fe). Como se puede apreciar, se trataba de un deber que subsiste a la extinción de las obligaciones principales de las partes, aunque cabe discutir si efectivamente la relación jurídica había perecido totalmente, en lo que tendrá incidencia la calificación de prescripción o caducidad del plazo establecido normativamente para el

${ }^{23}$ Corte Suprema, rol No 430-2010, de 7 de junio de 2011, cita online: CL/JUR/10077/2011.

${ }^{24}$ Corte Suprema, rol № 2073-2013, de 29 de junio de 2014, cita online: CL/JUR/2748/2014.

25 Corte Suprema, rol № 137-2010, de 4 de julio de 2011, N ID: CL/JUR/10081/2011. 
cobro de la deuda ${ }^{26}$. De manera similar, en Orellana Acosta con Banco de Crédito e Inversiones (2015) ${ }^{27}$, se condenó en primera instancia ${ }^{28}$ a la demandada al pago de \$5.000.000 por concepto de indemnización de perjuicios, por informar deudas a bancos de datos una vez que la cuenta corriente y la tarjeta de crédito Visa del actor se encontraban ya cerradas.

Con todo, vemos que estos dos últimos casos pudieron haberse demandado en sede de protección de los derechos de los consumidores, solicitando el resarcimiento de los daños sufridos (art. $3^{\circ}$ LPDC), lo que se evidencia en bastantes condenas por información de deudas a bancos de datos, una vez que ellas se encuentran extinguidas, sobre lo que se volverá más adelante.

Finalmente se puede citar la sentencia Jiménez Mira con Armijo Cerda (2011), la cual, aunque se pronuncia sobre un supuesto de responsabilidad precontractual, reitera la idea de que la buena fe debe acompañar todo el iter contractual, incluyendo la fase postcontractual ${ }^{29}$.

\section{La etapa postcontractual}

Recordemos que la perspectiva temporal del contrato abarca el análisis de la convención desde su etapa precontractual, hasta la postcontractual, incluyendo los vínculos de larga duración (long terms $)^{30}$. Así las cosas, y una vez revisado el panorama general acerca del concepto y reconocimiento de la responsabilidad en análisis, corresponde delimitarla, esto es, determinar su momento de inicio y de término, puesto que de ello se derivará el período de exigibilidad y eficacia de los deberes que le dan origen.

\subsection{Inicio de la etapa postcontractual}

La etapa postcontractual se caracteriza por iniciarse una vez que se han extinguido las obligaciones principales del contrato. A continuación se analizarán

\footnotetext{
${ }^{26}$ Acerca de la diferencia entre prescripción y caducidad y los efectos distintos a que ellas dan origen: ISLER (2017), pp. 59-109.

$279^{\circ}$ Juzgado Civil de Santiago, rol № C-12291-2011, de 24 de marzo de 2015, no obstante, se declaró prescrita la acción en Corte de Apelaciones de Santiago, rol № 10784-2015, de 25 de julio de 2016, se declara inadmisible el recurso de casación, Corte Suprema, rol № 62204-2016, de 5 de diciembre de 2016.

${ }^{28}$ El Tribunal de Alzada revocó la sentencia al considerar que se encontraba prescrita la acción.

${ }^{29}$ Corte Suprema, rol № 1872-2010, de 29 de diciembre de 2011.

30 LorenzetTI (sin año), p. 29. De acuerdo a los Principios Unidroit sobre contratos comerciales internacionales (2016), los de larga duración normalmente -aunque no necesariamente- llevan envuelta una complejidad en la transacción y una relación permanente entre las partes (art. 1.11).
} 
ambos elementos, así como la situación en el Derecho del Consumo, con una especial referencia al ordenamiento jurídico chileno.

\subsubsection{Los deberes secundarios del contrato}

Corresponde determinar qué se entiende por deberes colaterales, "laterales" ${ }^{31}$ o secundarios, puesto que si ellos tienen el carácter de principales, su incumplimiento se enmarcará dentro de la etapa contractual. Ahora bien, antes de entrar al análisis de su concepto, se debe prevenir que ellos no deben confundirse con los accesorios, puesto que estos últimos siguen la suerte de lo principal, lo que no ocurre necesariamente con los secundarios ${ }^{32}$, en el sentido de que aquellos que proceden postcontrahendo, precisamente subsisten no obstante la extinción de las obligaciones esenciales, razón por la cual Facco los denomina "deberes de fuente contractual con eficacia ultractiva" ${ }^{33}$. En efecto, ellos tienen un contenido autónomo, y operan con prescindencia de que la prestación principal se haya cumplido ${ }^{34}$.

Se debe tener presente, asimismo, que se ha insinuado la importancia de distinguir entre deberes principales y secundarios, ya en el Derecho Común, no sólo a propósito de la calificación de la responsabilidad de acuerdo al íter contractual, sino que también como mecanismo de configuración de ciertas instituciones. Así, por ejemplo, ha ocurrido en la resolución, tal como se mencionó en la ya aludida sentencia Inversiones Clarkson y Compañía Limitada con Donoso Caamaño (2014), en la cual el Tribunal estimó que no procedía en caso de incumplimiento de deberes secundarios (art. 1489 CC) ${ }^{35}$, cuestión que, en todo caso, no es pacífico en la doctrina nacional ${ }^{36}$. En la materia que

\footnotetext{
31 Varacalli y Picasso (1994), p. 235.

32 De acuerdo con un criterio de subsistencia, la obligación principal es aquella que "puede subsistir por sí sola y tiene un fin propio o representa el fin primario de la relación", en tanto que la accesoria "es aquella cuya existencia depende de otra a la cual sirve de medio para hacer posible, integrar o asegurar su cumplimiento", ambos en AlESSANDRI et al. (2004), p. 25. No obstante, el aludido Proyecto de Código Civil argentino de 1998, los calificaba de "obligaciones accesorias" (art. 1063 letra a).

33 FACCO (2009), p. 1.

34 SaAvedra (1996), p. 370.

${ }^{35}$ Corte Suprema, rol № 2073-2013, de 29 de mayo de 2014. En este caso, además, se estimó que procedía el derecho alternativo del art. 1489 CC, al considerarse que las falencias en las terminaciones e instalaciones de una casa -baldosas rotas, manchas por humedad en muros, deficiencias en ventanas de termopanel, instalación eléctrica incompleta, deficiencias en aislamiento, etc.- si bien constituyen incumplimientos, constituían incumplimientos graves.

${ }^{36}$ En contra Rodríguez (2008), Vol. 2, p. 228, ha señalado que el art. 1489 no distingue entre obligaciones relevantes y secundarias, por lo que procede frente a cualquier incumplimiento. Para VIDAL (2009), pp. 239 y 240, en tanto, no se debe atender al carácter principal o secundario de la
} 
nos convoca, por su parte, ello resultará relevante al momento de calificar a la garantía legal como supuesto o no originador de responsabilidad postcontractual, así como en la determinación de la inaptitud del producto -total o parcial- que se exige para que se cumplan sus presupuestos de procedencia (art. 20 LPDC).

Ahora bien, el criterio de distinción que debe utilizarse dice relación con el interés que los deberes buscan cautelar, esto es, si se refiere a la propia prestación o bien a uno anexo a ella ${ }^{37}$, lo que a su vez se determina de acuerdo a la finalidad del contrato, su tipo ${ }^{38}$, y las otras circunstancias concurrentes que procedan ${ }^{39}$. Al respecto cabe señalar que en el ámbito en estudio, si bien existen legislaciones que expresamente se refieren a la tutela del interés del consumidor $^{40}$, la nuestra omite un pronunciamiento en tal sentido, aunque igualmente queda en evidencia la intención del legislador de resguardar sus legítimas expectativas, por ejemplo, mediante la incorporación del derecho a retracto (arts. $3^{\circ}$ bis y $3^{\circ}$ ter LPDC), la garantía legal (arts. 18 a 22 LPDC), la integración publicitaria del contrato (arts. $1^{\circ} \mathrm{N}^{\circ} 4$ y 28 LPDC), así como en la sanción de la publicidad falsa o engañosa (arts. 28 y 33 LPDC).

Con todo, explica Lorenzetti que las obligaciones nucleares del contrato son aquellas "vinculadas directamente al cumplimiento del objeto" 41 , esto es, "a la definición típica del negocio, y a sus caracteres principales" 42 . Benítez en tanto, sostiene que se refieren a la "finalidad principal perseguida por las partes $^{\prime \prime 4}$. Tal ocurriría, por ejemplo, con la obligación de entregar una cosa y pagar el precio, por parte del vendedor y comprador respectivamente, en la

obligación, sino que al incumplimiento en sí mismo, y su incidencia en el interés del acreedor (de acuerdo a la economía y al contrato) así como la buena fe objetiva. Asimismo, se ha discutido acerca de la procedencia de la resolución por pago parcial de la deuda: AlESSANDRI et al. (1941), p. 76. AlESSANDRI (1939), pp. 166 y 167; y FUEYO (1958), p. 124, estiman que procede frente a cualquier incumplimiento. Peñallitlo (2007), p. 126, es de la opinión contraria, en razón del principio de conservación del contrato.

37 Larenz (1958-1959), p. 156; López (1976), p. 107; López (2005), p. 414; ReZzóNico (1999), p. 529.

38 FARíAs (2014), p. 1.

39 Boetsch (2015), p. 131; Larenz (1958-1959), p. 156; López (1976), p. 107; López (2005), p. 414.

40 Así art. 1, Ley № 1480, Colombia; art. 1 Ley № 1334, Paraguay; art. 8 letra b) LGDCU, España; arts. Il y 1 letra c) Ley № 29.571, CPDC, Perú; arts. 1 y 35 № 4 Ley No 45 Panamá; arts. 3 letra e) y 9 Ley $N^{\circ} 24 / 96$, Portugal.

${ }^{41}$ LORENZETTı ( $\sin$ año), p. 30.

42 Lorenzetti (sin año), p. 30.

43 Benítez (2013). 
compraventa ${ }^{44}$. Así las cosas, en este caso nos encontramos frente a la prestación propiamente tal, definida como "el comportamiento que debe observar el deudor para satisfacer el interés del acreedor, y se traduce en una acción positiva (dar, hacer) o en una negativa, es decir, en una abstención (no dar, no hacer $)^{\prime \prime 4}$.

Por su parte, los colaterales, son aquellos que se caracterizan por permitir una completa liquidación de los efectos de la relación contractual ${ }^{46}$. Ellos ya habrían tenido un reconocimiento en la Alemania de principios del siglo XX, con la apreciación de Staub acerca de que existirían ciertos imperativos que complementan igualmente la prestación (Leistung) ${ }^{47}$. Al respecto explica además Bernal Fandiño: "la obligación no se limita a un vínculo específico entre acreedor y deudor para la realización del deber de prestación, sino que, como relación jurídica, se complementa con una serie de deberes colaterales $^{\prime \prime 4}$.

Desde este punto de vista, no corresponden a la prestación directa, sino que a la esfera de su protección ${ }^{49}$, complementándola o sirviéndola ${ }^{50}$, propendiendo a su resultado útil ${ }^{51}$. En este sentido, señala Larenz, que hacen referencia a su preparación, forma de ejecución, cooperación eventualmente necesaria entre las partes y lo que las ellas mismas puedan esperar de la otra en virtud de la equidad ${ }^{52}$. Estos deberes tienen por fundamento el hecho de que cada una de las partes tiene la obligación de cooperar para que cada una, en el desarrollo de sus relaciones contractuales tenga en cuenta el interés, por ella conocido, de la otra y ajustar su conducta en tal sentido, evitando razonablemente un menoscabo, el cual, una vez surgido, debe ser indemnizado $^{53}$. Implican así, una cooperación recíproca ${ }^{54}$, una actitud de corrección

${ }^{44}$ LORENZETtı ( $\sin$ año), p. 30.

45 Alessandri et al. (2004), p. 7.

46 Solarte (2004), p. 305.

47 A partir de la interpretación de los §§ 286, 347 BGB de la época, Staub (1913), pp. 6 y 7.

48 Bernal (2013), p. 57.

49 Boetsch (2015), p. 130.

50 Benítez (2013); Bernal (2013), p. 42; Lorenzetti (sin año), p. 31; SaAvedra (1996), p. 370.

51 Betti (1969), p. 108.

52 Larenz (1958-1959), p. 154.

53 Boetsch (2015), p. 96.

${ }^{54}$ RezzónICo (1999), p. 482. 
y lealtad ${ }^{55}$ y fundamentalmente la necesidad de cada una de las partes de evitar o impedir cualquier conducta por la cual su contraria pudiera verse despojada o esencialmente reducidas sus ventajas patrimoniales ${ }^{56}$. Por otra parte, pueden ser calificados de duraderos -el cumplimiento de la prestación que los integran exige un tiempo más o menos largo- ${ }^{57}$, y continuados o permanentes ${ }^{58}$.

Con todo, los deberes secundarios, pueden ser de finalidad negativa -evitación de daños- o bien positiva -complemento de la prestación ${ }^{59}-$, como podría ser en el área del Derecho del Consumo, no informar deudas extintas a bancos de datos y poner en antecedentes de los consumidores acerca de la inseguridad sobreviniente de un producto ya introducido al mercado o incluso comercializado, respectivamente. Los efectos que se agregan a la indemnización pueden ser también distintos en uno y otro caso, como por ejemplo, la inhibición de una conducta o bien el cumplimiento forzado, respectivamente, lo que se entiende sin perjuicio de la responsabilidad infraccional que pudiera resultar procedente y que es propia de un sistema dualista de responsabilidad-sancionatoria y civil-, como lo es el chileno.

Como se verá, en la esfera del Derecho del Consumo, también se contemplan deberes de este tipo (por ejemplo, art. $3^{\circ}$ LPDC), aunque ello no significa que siempre tengan el carácter de secundarios, puesto que frecuentemente pueden enmarcarse dentro de una obligación principal, lo que se determinará de acuerdo al caso concreto. En concordancia con lo anterior, nuestros tribunales han tenido la oportunidad de pronunciarse al respecto, al conocer las causas sobre robos en estacionamientos gratuitos, cuando el consumidor ha realizado compras en el establecimiento comercial, casos en los cuales la mayoría ha estimado que se trata de un deber de seguridad asociado a la compraventa ${ }^{60}$.

\footnotetext{
55 Rodríguez (2015), pp. 940 y 941.

56 FacCo (2009), p. 1; Larenz (1958-1959), p. 156; López (1976), p. 107; López (2005), p. 414; RezZÓNICO (1999), p. 529.

57 Alessandri et al. (2004), p. 182.

58 Alessandri et al. (2004), p. 182.

59 Bernal (2013), p. 42; Lorenzetti (sin año), p. 31; Solarte (2004), p. 306. Se ha sostenido que, en general, son negativos: Boetsch (2015), p. 131. LeIva (2002).
}

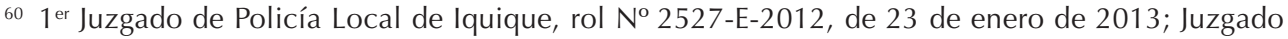
de Policía Local de Peñalolén, rol N² 29126-2-2010, de 12 de diciembre de 2012; 1 er Juzgado de Policía Local de Maipú, rol Nº 6340-2010, de 31 de enero de 2012, confirmada por la Corte de Apelaciones de Santiago, rol No 605-2012, de 23 de enero 2013; Juzgado de Policía Local de La Cisterna, rol No 33324-2-2011, de 25 de mayo de 2012, confirmada por la Corte de Apelaciones de San Miguel, rol No 1325-2012, de 3 de enero de 2013; $2^{\circ}$ Juzgado de Policía Local de San Bernardo, 
Ahora bien, si se presentan en la etapa postcontractual, por su satisfacción, se produce una completa y ordenada liquidación de los efectos derivados del contrato ${ }^{61}$, lo que implicará su agotamiento, esto es, el momento en el cual las partes han conseguido el objetivo por ellas perseguido ${ }^{62}$. Con todo, se debe tener presente que los deberes colaterales, no son exclusivos de la dimensión postcontractual, desde que también pueden encontrarse en la etapa previa ${ }^{63}$. Lo que ocurre es que en el estadio ultractivo son los únicos que subsisten.

Finalmente, cabe señalar que las partes pueden realizar una operación distinta, esto es, elevar a la categoría de esenciales, ciertos deberes que naturalmente no tendrían tal carácter, práctica que con frecuencia se ha transformado en una cláusula de estilo, principalmente cuando el objeto del contrato es un inmueble o presenta una alta cuantía. No obstante, ella puede ser examinada a la luz de nuestra regulación sobre abusividad de los pactos (art. 16 LPDC).

\subsubsection{La extinción de las obligaciones principales}

Si la etapa postcontractual se inicia una vez que se han extinguido las obligaciones principales del contrato, la doctrina en general ha mencionado al cumplimiento ${ }^{64}$ como el momento en el que ello ocurre, de tal manera que, desde esta perspectiva, la entrega del producto o la prestación de un servicio no harían caducar los deberes que autónoma o heterónomamente se han puesto de cargo del proveedor. En estos casos, coincidirá con lo que se ha denominado su consumación ${ }^{65}$ o agotamiento ${ }^{66}$, como explica Benítez: "una vez que las partes han cumplido con las prestaciones principales del contrato, estas siguen vinculadas como consecuencia del proceso de integración

rol № 3353-4-2008, de 24 de febrero de 2009, confirmada por la Corte de Apelaciones de San Miguel, rol № 301-2009, de 11 de mayo de 2009; Corte de Apelaciones de San Miguel, rol № 3002009, de 17 de junio de 2009, que confirma el $2^{\circ}$ Juzgado de Policía Local de San Bernardo, rol

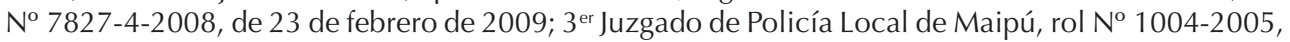
de 31 de diciembre de 2007, confirmada por la Corte de Apelaciones de Santiago, rol № 1724-2008, de 18 de junio de 2008.

${ }^{61}$ Martín (2004), p. 3114; Monsalve (2008), p. 47.

62 ReZzónico (1999), p. 529.

63 Leiva (2002); Lorenzetti (sin año), p. 31.

${ }^{64}$ Betti (1969), p. 104; Benítez (2013); Facco (2009), p. 1; Leiva (2002); Rodríguez (2015), p. 936; LóPEZ (1976), p. 100; LóPEZ (2005), p. 414; RodRíGuez (2015), p. 936.

${ }^{65}$ Solarte (2004), p. 305.

${ }^{66}$ Leiva (2002); Martín (2004), p. 3114. 
contractual que produce la buena fe en el mismo que impone a las partes un obrar con lealtad aun después de cumplidas las prestaciones principales" ${ }^{\prime 67}$.

Ahora bien, el cumplimiento se produce cuando se realiza la prestación convenida o establecida ${ }^{68}$, satisfaciéndose el rol y la finalidad que dieron origen a la obligación ${ }^{69}$. Como se puede apreciar, el objetivo perseguido por la convención, que en el punto precedente se había indicado como elemento que debe tomarse en consideración al momento de calificarse un deber como principal o secundario, esta vez, también sirve para determinar si la obligación ha sido o no satisfecha. Con todo, lo anterior además debe interpretarse en clave del principio de la buena $\mathrm{fe}^{70}$, puesto que informa también esta fase del iter negocial, y se ve reforzado por la vinculación que se advierte en el art. 16 letra g) LPDC entre este imperativo y la "finalidad del contrato".

Por otra parte, la noción contraria de incumplimiento también aparece como relevante, puesto que, mientras que la obligación no se entienda satisfecha, nos encontraremos dentro del campo de la responsabilidad contractual propiamente tal. En el Derecho común ello podría tener relevancia, habida consideración de la discusión que se presenta respecto del régimen jurídico aplicable a la transgresión de los deberes postcontrahendo, lo cual no se presenta en la disciplina que nos convoca, desde que la estructura de la LPDC permite la formación de un concurso de acciones, en el cual el legitimado activo puede optar por uno de los dos sistemas, de acuerdo con lo que se señalará en la parte final de este trabajo.

Valga mencionar, eso sí, que aquél existe cuando no se ha ejecutado la obligación, o bien cuando el cumplimiento es imperfecto o extemporáneo ${ }^{71}$. En este punto resulta interesante también la disputa que se ha presentado acerca de la aptitud extintiva de ciertos supuestos de observancia no integral, tal como ocurriría por ejemplo, con la entrega de un bien defectuoso. En el Derecho común, esta temática ha sido abordada por De la Maza, cuya propuesta considera que el vendedor ha cumplido, no sólo con una "simple tradición" sino que se requiere una "conformidad al contrato"72, esto es, con-

67 Benítez (2013).

${ }^{68}$ Abeliuk (2008), p. 620.

${ }^{69}$ Abeliuk (2008), p. 610. De la Maza (2013), p. 238, señala que el propósito de las partes se debe tener en consideración al momento de determinar el cumplimiento de la obligación de entrega de la cosa.

70 Betti (1969), p. 116.

${ }^{71}$ Corte Suprema, rol № 2073-2013, de 29 de mayo de 2014.

72 De la Maza (2012a), p. 658; De la Maza (2013), pp. 235 y 240. 
forme al propósito de las partes ${ }^{73}$. En el ámbito del Derecho de Consumo en tanto, la discusión, se ha presentado a propósito del grado de inaptitud que se exige para la procedencia de la garantía legal. Así, para unos, éste debe ser total -impide la utilización absoluta ${ }^{74}-$, y para otros basta con que sea parcial -disminuye la funcionalidad ${ }^{75}$-.

Con todo, se debe tener presente que la responsabilidad postcontrahendo puede configurarse cuando las obligaciones principales se han extinguido, sea que ello haya ocurrido por el pago o por otro modo de extinguir las obligaciones, aunque no sea satisfactorio para el acreedor ${ }^{76}$. Betti ha explicado: "el acreedor aun cuando queden insatisfechas sus expectativas, no puede considerarse, en cierto modo, como en estado de guerra con el deudor y comportarse de tal modo que aumente el daño del incumplimiento, desinteresándose de las consecuencias perjudiciales que su indiferencia produce en la esfera de los intereses de la otra parte"177.

Un ejemplo de lo anterior lo encontramos en la obligación de eliminación o cancelación de datos personales caducos en bancos de datos (art. $6^{\circ}$ Ley $\mathrm{N}^{0}$ 19.628), esto es, si han perdido actualidad por disposición de la ley, el cumplimiento de la condición o la expiración del plazo señalado para su vigencia, o por el cambio de los hechos o circunstancias que consigna (art. $2^{\circ}$ letra d Ley $\mathrm{N}^{\circ}$ 19.628). La misma normativa además exige que la información debe ser exacta, actualizada y responder con veracidad a la situación real del titular de los datos (art. $\left.9^{\circ}\right)$, lo que se ve refrendado por la prohibición de comunicar datos de carácter económico, financiero, bancario o comercial transcurridos cinco años desde la exigibilidad de la obligación, o bien de continuar informándola si se ha extinguido por cualquier medio, incluida la

\footnotetext{
73 De la Maza (2013), p. 238. Análisis jurisprudencial: De la Maza (2012b), pp. 95-114. Recordemos que, en la sentencia de la Corte Suprema, rol № 2073-2013, de 29 de mayo de 2014, la Corte Suprema estimó que los defectos de construcción importan el incumplimiento del contrato, de lo que se desprendería que no se trataría de deberes colaterales.

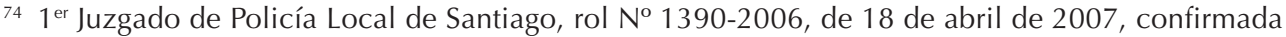

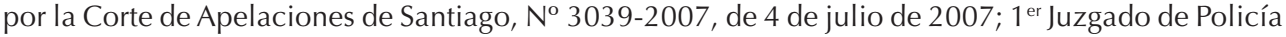
Local de Las Condes, rol № 83989-3-08, de 9 de diciembre de 2008; $2^{\circ}$ Juzgado de Policía Local de Puente Alto, rol No 46157-2-2007, de 15 de abril de 2008.

75 Corte de Apelaciones de Rancagua, rol № 29-2006, de 2 de octubre de 2006, en relación con

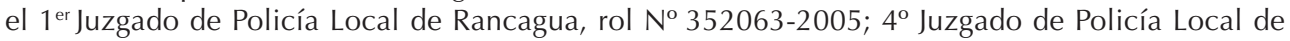
Santiago, rol № 79-6-06, de 14 de julio de 2006.

${ }^{76}$ Facco (2009), p. 5. Para Boetsch (2015), p. 130, procede tanto en el cumplimiento como en el incumplimiento. De acuerdo a VARACALLI y PICASSO (1994), p. 235, procede en la resolución, rescisión y revocación.

77 Betti (1969), p. 117.
} 
prescripción (art. $8^{\circ}$ ). De acuerdo con lo anterior, es que el proveedor-acreedor se encuentra obligado a poner en antecedentes a los bancos de datos en los cuales se encuentra informada una deuda, acerca de su extinción, con el objeto de que el deudor-consumidor sea removido de la nómina correspondiente. En sede de protección de los derechos de los consumidores, una conducta en contrario ha sido sancionada en diversas ocasiones, invocándose como normativa complementaria la señalada Ley $N^{0} 19.628$ (art. 19) ${ }^{78}$.

Por otra parte, en específico, el art. $3^{\circ}$ inc. $2^{\circ}$ letra c) LPDC consagra el derecho del consumidor financiero a ser liberado de las garantías constituidas en favor del proveedor, para asegurar el cumplimiento de las obligaciones, una vez que éstas se han extinguido. Esta norma se incluyó en la LPDC en el año 2011 con la entrada en vigencia de la Ley $N^{\circ} 20.555$, precisamente a raíz de la conducta de ciertos proveedores de no tramitar la cancelación de hipotecas, aunque se hubieren pagado todas las cuotas de los créditos para la compra de viviendas, con lo cual el inmueble continuaba figurando con un gravamen en el registro público.

\subsubsection{La situación en el Derecho del Consumo}

En materia de consumo, la procedencia de deberes en esta fase del iter contractual puede verse dificultada, a partir de la actualidad de una disputa que surgió con la entrada en vigencia de la Ley No 19.496 en el año 1997, referente al criterio que se debe utilizar para determinar su aplicabilidad. En efecto, la deficiente redacción de la Ley implicó que tanto en la definición de proveedor como de consumidor (art. $1^{\circ} \mathrm{N}^{\circ} \mathrm{s} .1$ y 2 LPDC) se aludiera a la exigencia de la celebración de un contrato oneroso y el cobro de un precio o tarifa, para que los sujetos puedan ser calificados de tal.

Conforme a una primera línea de interpretación, que tuvo amplia acogida en los inicios de la vigencia de la LPDC, dichos presupuestos implicarían que sólo podría ser invocado este estatuto tutelar, cuando se haya celebrado un negocio jurídico oneroso entre las partes ${ }^{79}$. Se veía reforzada esta tesis por el art. $2^{\circ}$ LPDC el cual, en concepto de esta doctrina, contendría el ámbito de aplicación de la LPDC, refiriéndose únicamente a contratos, dejando de lado cualquier hipótesis extracontractual.

\footnotetext{
${ }^{78}$ Condenas en tal sentido: $3^{\text {er }}$ Juzgado de Policía Local de Santiago, rol № 23618-DIO-2008, de 18 de marzo de 2010, confirmada por la Corte de Apelaciones de Santiago, rol № 1617-2010, de 28 de julio de 2010; Juzgado de Policía Local de Huechuraba, rol № 109890-6, de 29 de diciembre de 2009.

79 Jara (1999), pp. 48 y 51; Jara (2006), pp. 21-58; Ruiz-TAgle (2010), pp. 303-305. Jurisprudencia: Sernac y Quiroga Cavieres con Cencosud Supermercados S.A. Juzgado de Policía Local de Quilicura, rol № 10833-3-2008, de 26 de agosto de 2009.
} 
Afortunadamente, dicho criterio ha venido siendo abandonado progresivamente tanto por la literatura como por la jurisprudencia. En este sentido, cabe señalar que la LPDC es susceptible de ser aplicada tanto a situaciones contractuales como extracontractuales, de tal manera que el verdadero criterio de determinación es la relación de consumo ${ }^{80}$, la que se configura por un vínculo entre un proveedor y un consumidor, y que se encuentra consagrada en el inciso primero del mismo art. $1^{\circ}$ LPDC.

Existen diversos argumentos en orden a fundamentar lo anterior, los cuales no son objeto directo de este documento, por lo que únicamente se mencionarán. Así, en primer lugar, se debe recordar que la misma LPDC que incorporaba en sus definiciones de consumidor y proveedor alusiones al contrato oneroso y al cobro de un precio o tarifa, simultáneamente reconoce infracciones que no requieren de convención alguna para que se cumplan los presupuestos de los tipos contravencionales. Es más, incluso la propia negativa injustificada a contratar ya es sancionada (art. 13 LPDC). Otros casos los encontramos en el actuar de los guardias de seguridad (art. 15 LPDC), deberes de información (arts. 28 y 29 LPDC), entre otros. De esta manera, las definiciones invocadas por la tesis anterior son hoy en día anacrónicas y no alcanzan a explicar la naturaleza de la relación de consumo, llamando la atención que el propio legislador no haya decidido eliminar las referencias en cuestión -contrato oneroso y cobro de un precio o tarifa-, las que, en todo caso, no suelen encontrarse presentes en las legislaciones foráneas.

Por otra parte, recordemos que la enumeración de situaciones a las cuales se aplica la LPDC (art. $2^{\circ}$ LPDC) ${ }^{81}$ pasó de ser taxativa a ejemplificadora a partir de la entrada en vigencia de la Ley $N^{\circ} 19.9 .55$. Finalmente cabe señalar que el catálogo de garantías básicas consagradas en el art. $3^{\circ}$ LPDC,

\footnotetext{
${ }^{80}$ Cárdenas (1999), pp. 69-70; Fernández (1998), pp. 107-126; Isler (2010a), pp. 97-126; MomberG (2004), pp. 41-62; Momberg (2013a), pp. 3 y ss.; MomberG (2013b), pp. 66-76; MomberG Uribe (2013c), pp. 77-83; PINOCHET (2011), pp. 343-367. Jurisprudencia: Cavagnaro Hukdhs, Óscar Manuel con Johnsons S.A. Corte de Apelaciones de Valparaíso, rol № 473-2013, de 2 de diciembre de 2013; Cabrera Arenas con Entel PCS Telecomunicaciones S.A. $4^{\circ}$ Juzgado de Policía Local de Santiago, rol № 2228-5-2010, de 19 de octubre de 2010; Sernac y Meier Muller con Shell Chile S.A. $1^{\text {er Juzgado }}$ de Policía Local de Providencia, rol No 3305-2-2007, de 9 de enero de 2008, confirmada por la Corte de Apelaciones de Santiago, rol No 1800-2008, de 18 de junio de 2008; Sernac y Andrade con Embotelladora Unidas S.A. Juzgado de Policía Local de Renca, rol № 33862-1-2002, de 28 de marzo de 2007, confirmada por la Corte de Apelaciones de Santiago, rol № 6615-2007, de 9 de enero de 2008; Sepúlveda con Café Astoria Fucs y Compañía Limitada Corte de Apelaciones de Concepción, rol No 500-2005, de 8 de noviembre de 2007.

${ }^{81}$ Encabezado del art. 2 LPDC original: "Sólo quedan sujetos a las disposiciones de esta ley los actos jurídicos que, de conformidad a lo preceptuado en el Código de Comercio u otras disposiciones legales, tengan el carácter de mercantiles para el proveedor y civiles para el consumidor".
} 
que incluye el mencionado derecho a indemnización, son de reconocimiento amplio, de tal manera que son sus titulares tanto el consumidor concreto como el abstracto.

Ahora bien, esta discusión resulta relevante para la procedencia de los deberes postcontractuales, desde que la primera defensa de los proveedores una vez que han sido denunciados y demandados, radica en sostener la inaplicabilidad de la LPDC, la cual -en su concepto-sólo puede ser invocada cuando existe un contrato celebrado y vigente. De esta manera, una vez que este se ha agotado -mediante el cumplimiento de los deberes esenciales-, precluye también la posible aplicación de la LPDC, por lo que el legitimado activo necesariamente debe dirigirse a los Tribunales Ordinarios, demandando en virtud del Derecho común, si procediere.

A este respecto, cabe mencionar las sentencias recaídas en la causa Sernac con Farmacias Ahumada S.A. (2016), (2014) y (2013), y que se pronuncian respecto de la responsabilidad en sede de protección de los derechos de los consumidores, a partir de la colusión en que se vio involucrada la demandada con otros proveedores, al fijar concertadamente los precios de 220 medicamentos, entre diciembre de 2007 y marzo de 2008. Con posterioridad, la misma empresa se habría comprometido al cumplimiento de un Plan de Compensación que incluía ciertos beneficios destinados a reparar en cierta medida los daños patrimoniales causados a los consumidores. Por su parte, el Sernac, al estimar que dicho programa no había sido satisfecho íntegramente, la demandó por infracción a los arts. 12 y $3^{\circ}$ letra e) LPDC.

En esta ocasión, tanto las sentencias de primera instancia como la de casación acogieron la defensa de la demandada en orden a considerar que no podía ser considerada proveedora, de acuerdo con la definición del art. $1^{\circ}$ № 2 LPDC, al no existir al tiempo del desarrollo del citado Plan un vínculo contractual con sus beneficiarios, el cual sólo podía ser considerado una oferta (considerando $7^{\circ}, \mathrm{CS}$ ). Se desechó, por tanto, la tesis de la Corte de Apelaciones que sí reconocía la aplicabilidad de la LPDC, precisamente a partir de la configuración de la hipótesis en estudio. Así, en su considerando 24 señala: "lo contemporáneamente obrado por la apelada no es sino la prolongación de un mismo y solo acto jurídico de provisión de medicamentos" (considerando 24), posible de enmarcar en el art. $2^{\circ} \mathrm{N}^{\circ} 1$ LPDC, esto es, mixto o de doble carácter. Agrega que se trataría de una manifestación de la responsabilidad postcontrahendo, por incumplimiento de deberes laterales o secundarios del contrato, que se refieren a la entera satisfacción de la convención.

De esta manera, la línea de interpretación adoptada por el Tribunal de Alzada, acerca de la procedencia de la indemnización es correcta, de acuerdo 
con lo señalado con anterioridad en este trabajo, así como en la consideración de que la LPDC puede ser fuente tanto responsabilidad contractual como extracontractual. Por otra parte, aun de considerarse que sólo se aplica a los contratos de consumo, lo cierto es que el vínculo jurídico no se extingue con la satisfacción de los fines principales del contrato, desde que permanecen vigentes otros deberes de naturaleza secundaria, que se relacionan fundamentalmente con el imperativo de no dañar, por lo que caben dentro de la esfera de vigencia de la LPDC.

Afortunadamente también encontramos pronunciamientos judiciales en este sentido. En primer lugar, se puede mencionar la sentencia, Cavagnaro Hukdhs, Óscar Manuel con Johnsons S.A. (2013), que tuvo origen en la acción interpuesta por un consumidor, que había comprado un producto defectuoso. A consecuencia de lo anterior, concurrió a las dependencias de la denunciada para ejercer sus derechos derivados de la garantía legal, oportunidad en la cual sufrió un accidente a causa de unos colgadores que por negligencia se encontraban en el suelo. Como era de esperarse, la demandada se defendió sosteniendo la inaplicabilidad de la LPDC, argumentando que los daños se habían producido una vez que la compraventa celebrada entre las partes ya se había cumplido, por lo que con posterioridad a ello ya no existía relación de consumo alguna.

Por su parte el Tribunal, si bien estimó que el criterio de aplicabilidad de la LPDC era el del contrato de consumo, entendió que éste no perdía eficacia por la mera entrega del producto y el pago del precio, sino que con posterioridad a ello subsistían otros deberes intrínsecos, en este caso, de seguridad y resarcimiento. Por tal razón, condenó a la empresa al pago de una multa a beneficio fiscal y de los perjuicios ocasionados. De esta manera, el propio sentenciador reconoce que la tesis del contrato de consumo -la que, como se dijo, no se comparte-, no impide la resarcibilidad de daños postcontractuales.

También, en Vera Videla con Salcobrand $(2015)^{82}$, se condenó a la denunciada por infracción a los arts. 12 y 23 LPDC, y se le ordenó pagar una indemnización de \$5.000.000, en una ocasión en que algunos dependientes de la farmacia concurrieron al domicilio de la actora acusándola de hurto de ciertos medicamentos, oportunidad en la cual esta última les exhibió la boleta de la compra. Esta vez, igualmente la Corte Suprema terminó condenando a la empresa, aun cuando los hechos se habían producido luego de tres horas de celebrada la compraventa y cumplidas sus prestaciones.

${ }^{82}$ Corte Suprema, rol No 10546-2015, de 30 de septiembre de 2015, acoge recurso de queja interpuesto respecto de la Corte de Apelaciones de Valparaíso, rol № 315-2015, de 5 de agosto de 2015. 


\subsection{Término de la etapa postcontractual}

El período en el cual los deberes postcontractuales son exigibles, dependerá de si tienen un origen heterónomo o autónomo. Si se trata de deberes secundarios expresamente establecidos en el contrato, regirá el plazo de extinción que él mismo indique, el cual en todo caso no puede ser inferior a aquel que se obtiene de las reglas contempladas para la prescripción y caducidad en el ordenamiento jurídico. Lo anterior, puesto que una cláusula en tal sentido podrá ser declarada abusiva conforme al art. 16 letras e) y g) LPDC, esto es, por contener limitaciones de responsabilidad y atentar contra la buena fe, respectivamente, sin perjuicio de la invocación de las normas sobre objeto ilícito del Derecho común (arts. 10, 1466 y 1682 CC) ${ }^{83}$.

Por su parte, si el imperativo tiene origen en una norma jurídica que lo consagra específicamente, rige igualmente el término en ella mencionado, salvo que dicha disposición ceda ante otra, en razón de la aplicación de algún criterio de resolución de una eventual antinomia que pudiera llegar a configurarse.

Ahora bien, en caso de que el deber provenga del reconocimiento genérico de la buena fe, o bien, si tiene por fuente el contrato o una norma particular, pero que no expresan un término, o bien contemplándolo no es procedente -por ejemplo por abusividad-, regirán los plazos comunes de la prescripción liberatoria ${ }^{84}$.

En el ámbito del derecho del Consumo, la cuestión de la prescripción implica una problemática de extensa discusión, que no alcanza al objeto directo de esta investigación, pudiendo revisarse una publicación más extensa que existe al respecto ${ }^{85}$. No obstante, cabe señalar que el art. 26 LPDC se refiere hasta el momento únicamente a la acción contravencional, consagrando un plazo de 6 meses contado desde la infracción respectiva. Esta omisión, a la que se agrega también la ausencia de una mención del régimen supletorio,

\footnotetext{
${ }^{83}$ Las cláusulas que disminuyan los plazos de prescripción son ineficaces: BARCIA (2013), p. 638; Contreras (2009), p. 581; GHeRsi (1999), p. 98; Isler (2017), pp. 313-326.

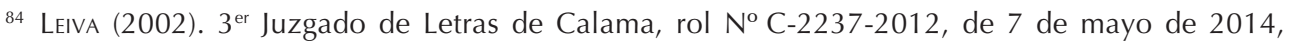
finalmente se celebró transacción, Corte de Apelaciones de Antofagasta, rol № 626-2014, de 22 de diciembre de 2014. Según FAcco (2009), p. 3, estos deberes son exigibles hasta que se haya verificado el hecho extintivo que las partes pactaron o bien si ello no se ha estipulado, hasta que su observancia sea relevante, esto es, mientras subsista el interés digno de tutela que lo justifica, pudiendo corresponder en este último supuesto la fijación por el juez de un plazo máximo razonable a pedido de la parte interesada, para lo cual se podría recurrir a un plazo de prescripción, cuyo régimen tampoco se encuentra definido. Excepción a ello, sería el secreto profesional que se mantiene durante toda la vida, salvo que concurra alguna de las causales por las cuales éste termina.

${ }^{85}$ ISLER (2017), pp. 29-330.
} 
ha conllevado que no exista claridad acerca del término que debe regir para la responsabilidad civil, dentro de la cual encontramos a la postcontractual. Asimismo, la vigencia de la regulación propia de los Juzgados de Policía Local (Leyes $\mathrm{N}^{\circ}$ s.15.213 y 18.287) ha permitido que surjan dos posibles respuestas: la aplicación del exiguo plazo de seis meses consagrado en el citado art. 26, o bien de los términos del Derecho común. Aunque la doctrina ampliamente mayoritaria se ha pronunciado en este último sentido ${ }^{86}$, la jurisprudencia dominante ha optado por la solución contraria ${ }^{87}$, al considerar a las acciones civiles como accesorias de la infraccional ${ }^{88}$.

\section{La fuente de los deberes postcontractuales}

Los deberes postcontractuales, como se indicó, pueden ser negociales o heterónomos, lo que tendrá incidencia en el examen de su licitud y procedencia.

\subsection{Los deberes postcontractuales negociales}

Las partes pueden incorporar al contrato deberes postcontractuales, los cuales pasan a llamarse negociales. La aptitud para establecer pactos de este tipo se deriva del principio de la autonomía de la voluntad, aunque en ocasiones también cuenta con un reconocimiento normativo.

Así, por ejemplo, recordemos que el Proyecto de Código Civil argentino de 1998, expresaba que podían tener por fuente la estipulación de las partes o bien estar virtualmente comprendidas en el contrato (art. 1063 letra b). Lo propio ocurre con el reconocimiento positivo de las garantías de postventa convencionales -en Chile art. 21 LPDC-, las que en ningún caso pueden restringir, limitar o suprimir los derechos que la propia legislación ha conferido a los consumidores con carácter irrenunciable (art. $4^{\circ}$ LPDC), entre ellos, los que origina el régimen de la garantía legal (arts. 19 y siguientes LPDC).

De la misma manera, como se indicó, pueden derivarse del amplio campo de la autonomía de las partes, como lo reconocieron también las sentencias ya

\footnotetext{
${ }^{86}$ A modo ejemplar: Barcia (2012), p. 153; Barrientos (2011), p. 269; Barrientos y Contardo (2013), p. 582; Corral (1999), p. 209; Corral (2011), p. 128; Isler (2010), p. 338; Isler (2017), pp. 29-330.

${ }_{87}$ A modo ejemplar, $2^{\circ}$ Juzgado de Policía Local de Punta Arenas, rol № 2972-2006, de 26 de julio

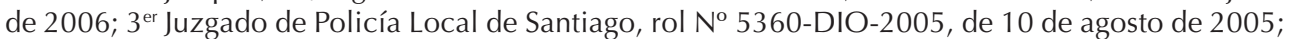
Corte de Apelaciones de Santiago, rol No 5380-09, de 2 de junio de 2009, que confirma la sentencia del Juzgado de Policía Local de Renca, rol № 8029-1-06, de 9 de diciembre de 2008, se declara inadmisible recurso de queja, Corte Suprema, rol № 3774-09, de 15 de julio de 2009.

${ }^{88}$ ISLER (2017), pp. 115-162.
} 
invocadas, Palacios Krogh con Stone Cereceda (2011) $)^{89}$ e Inversiones Clarkson y Compañía Limitada con Donoso Caamaño $(2014)^{90}$, las cuales mencionaban como fuentes de la responsabilidad postcontractual, el incumplimiento de deberes no esenciales contemplados en el propio contrato, a saber, la no construcción de caminos de acceso a las parcelas previamente adquiridas y defectos de construcción, respectivamente. En otras sedes, en tanto, se ha citado la cláusula de no trabajar para la competencia luego de terminado un contrato laboral ${ }^{91}$.

Con todo, las convenciones pueden incorporar imperativos de este tipo tanto de cargo del proveedor como del consumidor o ambos. Por otra parte, si se encuentran contenidos en un contrato celebrado por adhesión -que es la regla general en materia de consumo- su licitud debe ser revisada a la luz de las disposiciones reguladores de las cláusulas abusivas (principalmente el art. 16 LPDC).

\subsection{Los deberes postcontractuales heterónomos}

Los deberes pueden además provenir de una norma, en cuyo caso toman el nombre de heterónomos, al ser incorporados por un agente externo a la convención. Esta vez, puede darse el caso de que la disposición los mencione de manera específica, o bien se pueden desprender de la consagración general de la buena fe como principio inspirador, interpretativo e integrador del contrato, que se presenta en la mayoría de las legislaciones (art. 1546 CC chileno).

\subsubsection{Algunos deberes postcontractuales especialmente consagrados en el Derecho del Consumo}

Los deberes postcontractuales consagrados de manera específica en algunas normas no son privativos del Derecho del Consumo, toda vez que también podemos encontrarlos en otros estatutos, o incluso en los regímenes comunes, tal como ocurre con el de custodia (art. 1477 CC italiano) ${ }^{92}$, los de liquidación de regímenes patrimoniales del matrimonio ${ }^{93}$, entre otros.

\footnotetext{
${ }^{89}$ Corte Suprema, rol № 430-2010, de 7 de junio de 2011.

${ }^{90}$ Corte Suprema, rol № 2073-2013, de 29 de mayo de 2014.

${ }^{91}$ Gómez (2007), p. 10. Acerca de la validez de la cláusula de no competencia postcontractual en el contrato de trabajo: SierRA (2014), pp. 109-156.

92 Betti (1969), p. 105.

93 Martín (2004), p. 3114.
} 
Dentro de las normativas reguladoras de la relación de consumo, destacan los deberes de postventa, los cuales tienen lugar, una vez que se han cumplido las obligaciones esenciales de la compraventa, esto es, cuando se ha pactado el precio y se ha entregado el producto. Por tal razón, efectivamente tienen lugar en la esfera postcontractual ${ }^{94}$, tal como también se ha predicado de la evicción o los vicios redhibitorios del Derecho común ${ }^{95}$. Es más, de acuerdo con los regímenes de garantía, sólo tienen lugar una vez que el consumidor ha recibido el bien objeto del contrato, lo que implica que constituyan una prolongación del tiempo correspondiente a la expectativa de cumplimiento ${ }^{96}$.

Ahora bien, en nuestra legislación se encuentran consagrados en los arts. 19 a 22 LPDC, bajo el nombre de garantía legal, y cuyo supuesto general exige que se configure alguna de las causales del art. 20 LPDC, luego de lo cual el consumidor tendrá derecho a optar entre el cambio del producto, su reparación o la devolución del precio, además de una indemnización por los perjuicios sufridos. Con todo, se trata de un derecho eventual, esto es, que no requiere de un acto posterior del proveedor para que surja, sino que proviene de otra circunstancia causal, coetánea a la entrega de la cosa pero que se manifiesta con la advertencia de la defectuosidad. No se trata entonces de una "simple o mera expectativa" -se ha configurado el derecho- ${ }^{97}$, por lo que sí es transmisible aun antes de que se cumpla alguno de los supuestos del art. 20, a diferencia de otros deberes secundarios que surgen una vez que el proveedor los ha incumplido. Lo que puede quedar pendiente es simplemente la advertencia del daño que en su origen ya existía.

En segundo término encontramos el deber colateral de seguridad ${ }^{98}$, reconocido en la LPDC en su art. $3^{\circ}$ letra d) que consagra el derecho básico de los consumidores a "la seguridad en el consumo de bienes o servicios, la protección de la salud y el medio ambiente". Suele diferenciarse esta hipótesis de la anterior, a partir de la clasificación de los productos defectuosos en inaptos e inseguros, según si el defecto afecta a la seguridad o a la utilidad del bien. Con todo, este deber tiene por objeto evitar la lesión de intereses

\footnotetext{
${ }_{94}$ Por ejemplo, en Argentina se calificaba de tal la responsabilidad del constructor por ruina de obra (art. 1646 CC), Varacalli y Picasso (1994), p. 237.

95 Benítez (2013); Leiva (2002).

${ }^{96}$ LORENZEtTI (sin año), p. 32.

97 Alessandri et al. (1971), p. 277.

${ }^{98}$ En general es un deber secundario, salvo que se trate de un contrato en que la prestación principal sea de seguridad, como ocurre, por ejemplo, con los sistemas de vigilancia, prestaciones médicas, etc. Le Tourneau (2004), p. 106; Solarte (2004), p. 304. Según Le Tourneau (2004), p. 106, se justifica por la situación de desigualdad de las partes contratantes.
} 
no sólo patrimoniales sino que también personales de la contraparte ${ }^{99}$, por lo que involucra bienes jurídicos no disponibles. Puede, por otra parte, revestir manifestaciones diversas, pudiendo citarse, a modo de ejemplo, el derecho del consumidor de ejercer la garantía legal en condiciones inocuas - Cavagnaro Hukdhs, Óscar Manuel con Johnsons S.A.; a estacionarse en un local comercial seguro; a que no se le cobre indebidamente en razón de cuentas bancarias ya cerradas; etc. También cabe recordar la sentencia Vera Videla con Salcobrand (2015) ${ }^{100}$, referente al actuar de los funcionarios de seguridad.

En la misma línea se encuentra el deber del proveedor de informar a la autoridad de la peligrosidad o inseguridad advertida de un producto una vez que ya se ha incorporado al mercado -el consumidor puede ya haberlo adquirido- (art. 46 LPDC) ${ }^{101}$, así como a los consumidores (art. 45 LPDC); o bien la realización de Recall o llamados de retorno o cambio de productos inaptos o inseguros (art. 48 LPDC). Ello ha dado lugar a que con cierta frecuencia podamos reconocer en los medios de comunicación, así como en las propias páginas web institucionales, avisos de fabricantes que ofrecen al consumidor cambios gratuitos de productos o de alguna de sus partes -en Chile, mayoritariamente automóviles-, una vez que se ha tomado conocimiento de su imperfección. En general, ello se genera a partir de la presencia de defectos de diseño, esto es, aquellos en que la propia estructura o arquitectura del bien ha sido concebida erróneamente, por lo que afectan a toda una serie o partida de productos. Esta práctica tiene por objeto, en primer lugar, tutelar la seguridad de los consumidores, que es un bien jurídico extrapatrimonial -piénsese en un auto, al que no funcionan los frenos-, pero también puede evitar al proveedor, en ciertas ocasiones, el pago de indemnizaciones cuantiosas a causa de lesiones a la persona o bienes de los usuarios.

Este último, además, constituye una manifestación de otro deber que a veces adquiere el carácter de colateral postcontractual, cual es, el derivado del derecho -también básico- a una información veraz y oportuna sobre

\footnotetext{
99 Solarte (2004), p. 307.

100 Corte Suprema, rol № 10546-2015, de 30 de septiembre de 2015, acoge recurso de queja interpuesto respecto de la Corte de Apelaciones de Valparaíso, rol № 315-2015, de 5 de agosto de 2015.

101 Según López (2009), p. 1058, el art. 46 LPDC se refiere a los riesgos de desarrollo, que no son indemnizables en Chile, siempre que el proveedor los ponga en conocimiento de la autoridad competente, para que sea ésta la que tome las medidas preventivas o correctivas correspondientes. No se comparte esta tesis, puesto que también es de cargo del proveedor tomar todas las providencias necesarias para evitar e indemnizar daños.
} 
los bienes y servicios (art. $3^{\circ}$ letra b LPDC) ${ }^{102}$. Lo mismo ocurre en caso de que un consumidor haya mantenido una relación crediticia con una casa comercial y deba obtener un certificado de extinción de la deuda, para trámites posteriores.

Por otra parte, el derecho a una no discriminación arbitraria (art. $3^{\circ}$ letra c), implica la necesidad del proveedor de no transgredir la dignidad del consumidor en ningún momento, ni aun cuando ya se ha celebrado la compraventa y se han cumplido sus prestaciones.

Asimismo, el art. $3^{\circ}$ letra e) contempla la garantía a "la reparación e indemnización adecuada y oportuna de todos los daños materiales y morales en caso de incumplimiento de cualquiera de las obligaciones contraídas por el proveedor". Como se puede advertir, esta disposición consagra de manera amplia el derecho a resarcimiento que tiene todo consumidor que ha sido lesionado en sus derechos, lo cual, frente a la no distinción de la norma, se aplica a toda la responsabilidad civil, sea extracontractual o contractual, incluyendo las fases precontractual y postcontractual.

Recordemos también el art. $3^{\circ}$ inc. $2^{\circ}$ letra c), que obliga al proveedor a liberar las garantías constituidas en su favor, para asegurar el cumplimiento de las obligaciones una vez que éstas se han extinguido.

Finalmente cabe señalar que en el sistema de protección de los consumidores, son diversos los imperativos postcontrahendo, puesto que a los contemplados en la LPDC se agregan aquellos que se originan en su normativa sectorial, tal como ocurre con el ya aludido deber de eliminar deudas en bancos de datos (Ley $N^{\circ}$ 19.628). Este último es una manifestación del deber de secreto o reserva ${ }^{103}$, de amplia procedencia ${ }^{104}$, que surge, como explica Barros Bourie "cuando la parte que entrega la información puede razonablemente esperar que su privacidad sea respetada"105.

\subsubsection{La buena fe}

En caso de que los deberes postcontractuales no sean incorporados explícitamente al contrato por las partes o bien por otra norma jurídica, rigen

${ }^{102}$ CoRbetti (2010), p. 669, define a la obligación de información como "aquella que pesa sobre una de las partes a suministrar a la otra todo tipo de elementos que puedan clarificar el consentimiento o durante su ejecución".

103 López (2005), p. 415; Solarte (2004), pp. 304 y 310.

104 Respecto de los establecimientos de comercio, se sostiene que las cláusulas de no competencia que operan una vez que ha terminado una relación laboral buscan -entre otras cosas- que no se divulguen secretos de fabricación, o inventos industriales o de relación con la clientela, etc., BeNítez (2013).

105 Barros (2014), p. 554. 
igualmente aquellos que se derivan de la buena fe ${ }^{106}$, cuya misión integradora y potencialidad jurígena ${ }^{107}$ les otorga plena exigibilidad ${ }^{108}$. En nuestro sistema jurídico, como se adelantó, la fuente directa de lo anterior la encontramos en el art. 1546 CC $^{109}$-imperativo y de orden público ${ }^{110}$, , como señala Arias Barrera: "Dicha exigencia indica que aunque las partes no hayan sido lo suficientemente explícitas para integrar el contenido contractual, ese marco negocial puede configurarse con otros deberes que busquen de manera genuina el interés de las partes"111.

Por su parte, el Proyecto de Código Civil de 1998 de Argentina señalaba también que los deberes postcontractuales tenían como fundamento la buena fe (art. 1063), cuya extensión y alcance podían tener como fuente la estipulación de las partes o bien una regla tácita ("virtualmente comprendidas en el contrato"). Como se puede apreciar, aunque se concibe la posibilidad de que los deberes sean implícitos o expresados por la convención, en todo caso se sustentarán sobre el principio en comento, lo que llevó a alguna doctrina a sostener que a partir de entonces no era sólo un contrapeso a la libertad y estabilidad contractual, sino que también el eje de las relaciones jurídicas en general ${ }^{112}$.

Al respecto, explica también Barros Bourie, que la función de la buena fe es "completar el contenido del contrato, más allá de lo expresamente pactado o previsto por la ley, con el contenido normativo que se entiende atendida la naturaleza de la obligación o que lo que establece la costumbre"113. Por su parte para Solarte Rodríguez "a través de ella se dota de un sentido más amplio a los deberes creados por el negocio jurídico y también se crean una serie de deberes especiales, que atienden particularmente a la naturaleza del contrato y a su finalidad"114.

106 Boetsch (2015), p. 130; Le Tourneau (2004), pp. 104 y 105; Monsalve (2008), p. 46; Solarte (2004), p. 304.

107 BOETSCH (2015), p. 78.

108 Boetsch (2015), pp. 93 y 94; Monsalve (2008), p. 47. Jurisprudencia: Corte Suprema, rol No 430-2010, de 7 de junio de 2011.

109 Referencia histórica de la norma: GuZmán (2002), pp. 11-14. Alessandri et al. (1942), p. 270, explican que actualmente -a diferencia de Roma- no existen los contratos de estricto derecho, por lo que todos deben cumplirse de buena fe.

110 Boetsch (2015), p. 78. La buena fe es imperativa: Rezzónico (1999), p. 487.

111 El autor comenta el art. 1603 C.C. colombiano, similar a nuestra norma: ArIAS (2008), p. 25.

112 Picasso (2007), p. 78.

113 Barros (1999), p. 20.

114 Solarte (2004), p. 301. 
Con todo, esta falta de necesidad de alusión convencional ha llevado a algunos a sostener que se trataría de elementos de la naturaleza del negocio jurídico (art. $1444 \mathrm{CC})^{115}$, y por tanto incorporados por el legislador en él ${ }^{116}$. Serían así, normas supletivas que se refieren a aspectos no esenciales y que tienen por objeto integrar "lagunas contractuales"117. No obstante, se debe recordar que ellos se caracterizan por ser susceptibles de ser suprimidos por las partes ${ }^{118}$, en circunstancias de que, de acuerdo con los estatutos reguladores de la relación de consumo, los derechos de los consumidores -salvo los especialísimos casos excluidos por el propio legislador-, son de reconocimiento imperativo, irrenunciables anticipadamente (art. 4 LPDC), y no pueden ser modificados por la vía convencional, de tal manera que cualquier cláusula en tal sentido sería nula y de ningún valor (art. 16 LPDC y art. 1682 CC). Queda en evidencia, en este punto, que la remisión al Derecho común como régimen supletorio que se postulará procederá en la medida de que ello se avenga con la naturaleza de las relaciones de consumo. Esclarecedora resulta asimismo en este punto la consideración de Guzmán Brito acerca de que las expresiones del art. 1444 "cosas (...) de la naturaleza de un contrato" (1444) y "cosas que emanan de la naturaleza de la obligación" (art. 1546 CC), no serían equivalentes ${ }^{119}$, desde que las primeras son supletorias y pueden ser excluidas por las partes, en tanto que, en el segundo caso, se debe revisar en el supuesto concreto si se integran o no, por lo que la coincidencia podría ser solo parcial ${ }^{120}$. Ahora bien, al tratarse de deberes, resulta conveniente considerarlos efectos jurídicos, más que elementos, como había postulado Enneccerus ya hace un tiempo 121 , entendidos como "consecuencias no queridas, en tanto no se haya establecido otra cosa"122.

A continuación, cabe entonces preguntarse, cuáles son estas reglas, o, en otras palabras, a qué nos obliga esta integración ${ }^{123}$. En el ámbito del Derecho común, López Santa María postula que se trata de una buena fe objetiva, por

\footnotetext{
115 Se refiere a normas similares del CC. colombiano: SOLARTE (2004), pp. 296 y 297.

116 Alessandri et al. (1942), p. 26; Alessandri et al. (1971), p. 322.

117 Monror C. (2016), p. 223.

118 Los elementos de la naturaleza pueden faltar sin que el contrato varíe: AlESSANDRI et al. (1942), p. 26.

119 GuZMÁn (2002), p. 16.

120 GuZMán (2002), pp. 17 y 18.

121 ENNeCCERUS (1948), p. 290.

122 EnNeCCerus (1948), p. 290.

${ }^{123}$ Neuberger (2014), p. 10.
} 
ser ésta la propia de la responsabilidad contractual124, entendida como "un estándar legal, un parámetro flexible cuyo manejo y concreción, en cada caso, queda entregado al criterio, prudencia y sabiduría del juez de la causa"125. Boetsch Gillet, en tanto, boga por la vigencia de un carácter unitario que no la distingue de la subjetiva, al originarse ambas en un mismo principio que tiene naturaleza ontológica ${ }^{126}$. La LPDC, por su parte, nada dice acerca de la aplicación de un mecanismo u otro a propósito de la responsabilidad, sino que únicamente menciona como presupuesto de configuración de una de las causales de abusividad de las cláusulas, el atentado contra la buena fe, que se debe determinar de acuerdo a "parámetros objetivos" (art. 16 letra g LPDC), lo que ha llevado a Momberg Uribe y Pizarro Wilson a decantarse precisamente por la calificación objetiva, aunque sólo se refieren a este supuesto ${ }^{127}$. Ahora bien, en la parte final de este trabajo se indicará que, en caso de un incumplimiento contractual, se formará un concurso entre la responsabilidad civil autónoma y la derivada de la infracción, por lo que el estatuto dependerá de la elección del titular del derecho lesionado o no satisfecho.

Con todo, los deberes de la buena fe serán distintos, según el iter contractual en el cual procedan o bien si es extracontractual ${ }^{128}$, por lo que "conduce a una concepción sustancial y no meramente formal del principio de exactitud, permitiendo la posibilidad de adoptar un criterio más elástico, a ser apreciado en los límites de una tolerabilidad considerada normal o razonable en vistas de la funcionalidad de lo prestado"129. Implican, en todo caso, una actitud activa de parte del deudor ${ }^{130}$-no se compone sólo de abstenciones-, todo lo cual propende al resguardo de un interés ajeno ${ }^{131}$, como explica Facco: "En la ejecución del contrato y de la relación obligatoria, la buena fe se especifica, entonces, como precepto de salvaguardia, e impone a cada una de las partes actuar en modo de preservar los intereses de la otra,

124 LÓPEZ (1976), p. 99.

125 Corte Suprema, rol No 1872-2010, de 29 de diciembre de 2011.

126 Boetsch (2015), p. 65. En el mismo sentido: SaAvedra (1996), p. 365; Peñailillo (1996), p. 40.

127 Momberg y Pizarro (2013), p. 324.

128 Benítez (2013); Conde (2007), p. 202.

129 Facco (2009), p. 2. Según Neuberger (2014), pp. 1 y 2, el juez al fallar e interpretar el contrato debe considerar, no sólo el soporte en el cual se encuentre contenido (supuesto documental), sino que también las circunstancias externas (supuesto fáctico) y el aspecto comercial. Por otra parte, se debe considerar que, en la práctica y habida consideración del consensualismo que opera en los sistemas negociales, resulta que muchas convenciones no constan en papel.

130 Betti (1969), pp. 77 y 118; Facco (2009), p. 2.

131 Betti (1969), pp. 77 y 118; Facco (2009), p. 2. 
con prescindencia de obligaciones contractuales particulares y del deber extracontractual de neminemlaedere. Se trata en esencia de un compromiso de solidaridad, que se proyecta más allá del contenido de las obligaciones y de los deberes de respeto por el otro, y encuentra un preciso límite en el interés propio del agente"132.

Ahora bien, la buena fe en esta fase evoca la idea de rectitud, corrección ${ }^{133}$, cuyo deber asociado -lealtad-se presenta en aquellas relaciones jurídicas en que el elemento confianza es estructural ${ }^{134}$, manifestándose en la exigencia de comportarse correctamente en relación al otro, observando los deberes propios, buscando evitar los fraudes, abusos de confianza, y otras situaciones que pueden comprometer a la contraria, causándole perjuicios ${ }^{135}$.

Para Ilenarlo de contenido, resulta útil recurrir al criterio de la confianza razonable como parámetro de quiebre de la diligencia esperada. Este mecanismo, que ya ha sido utilizado por la doctrina para la configuración de la responsabilidad precontractual ${ }^{136}$, resulta también adecuado para los casos de culpa postcontrahendo. De esta manera, infringirá al proveedor los deberes de cuidado, cada vez que transgreda los imperativos que el consumidor legítimamente pudiera esperar de su contraparte, de acuerdo a la confianza que le merezca el contenido del contrato, integrado por la legislación. En otras áreas del Derecho, se han citado, como una concreción de ello, el deber de custodia, aviso y rescate ${ }^{137}$, la no realización de un acto de competencia desleal fuera de una cláusula de no concurrencia ${ }^{138}$, la permisión al antiguo arrendatario de poner carteles con la nueva dirección ${ }^{139}$; etc. En el dominio del consumo, en tanto, se pueden mirar como exigencias de este tipo, la no divulgación de datos sensibles, la no mantención de deudas no informadas al momento de cerrar una cuenta o tarjeta, etc.

\footnotetext{
132 FACCO (2009), p. 2.

133 Reveco (2010), p. 784; Varacalli y Picasso (1994), p. 237. Jurisprudencia: Corte Suprema, rol N $1872-2010$, de 29 de diciembre de 2011. Según VerA (2014), p. 98, encuentra su fuente en la buena fe-lealtad objetiva, en cuanto impone una conducta esperable de aquellos que intervienen con honradez en el tráfico jurídico y no una mera convicción de actuar debidamente.

134 Reveco (2010), p. 784.

135 VERA (2014), p. 83.

136 Un interesante análisis acerca de la buena fe, a partir de los deberes precontractuales, se encuentra en Zuloaga (2015), pp. 351-355. §§ 241 y 311 BGB.

137 SAAVEDRA (1996), p. 370.

138 Tallos del Río (2017), pp. 3-23.

139 Le Tourneau (2004), p. 103; López (1976), p. 107; Solarte (2004), p. 304.
} 
Con todo, se debe tener presente que, si bien la diligencia debida corresponde al "empeño normal en el cumplimiento de la convención"140, se la debe ponderar según el sujeto obligado. En efecto, en el Derecho del Consumo, el cuidado exigible al proveedor es mayor que aquel que se espera del consumidor, habida advertencia de las situaciones de asimetría -información, poder de negociación, propiedad de los medios de producción- que separan a las partes de la relación jurídica, y que implican que sea el primero quien se encuentra, por regla general, en mejores condiciones de evitar el daño, y, en todo caso, a un menor costo ${ }^{141}$.

\section{Régimen jurídico aplicable}

Desde un tiempo a esta parte, se ha comenzado a considerar la posibilidad de que se trate unitariamente la responsabilidad civil, la que englobaría, por tanto, los supuestos contractual y extracontractual. Ello se ha traducido, por ejemplo, en la vigencia de un plazo común de prescripción en el BGB luego de la reforma al Derecho de Obligaciones (§ 195 BGB), o bien en la propia regulación en el propio Soft Law (DCFR) ${ }^{142}$. Lo anterior, por cuanto la procedencia de un sistema binario de resarcibilidad de daños, como el que se encuentra plasmado en la mayoría de las legislaciones, puede llevar a situaciones de discriminación e inseguridad litigiosa.

Por otra parte, su conveniencia es aún más discutible en materia de consumo. Piénsese, por ejemplo, lo que ocurre en aquellos casos en que el adquirente regala el producto que compró, a otro sujeto, quien será finalmente

140 VERA (2014), p. 82.

141 Por tal razón, si bien en el Derecho común, se permite la condonación de la culpa leve y la levísima -se prohíbe la de la culpa grave- art. 1229, C.C. Italia; art. 100, ZGB Suiza; art. 1102 C.C. España; § 276 BGB; art. 1522 C.C. Colombia; art. 1465 C.C. Chile. Doctrina: De Verda y Beamonte (2005), pp. 37 y 39; González (2011), p. 94; PALermo (1969), p. 178. Sobre la asimilación de la culpa grave al dolo, se puede revisar: BARCIA (2006), pp. 75-95; BANFI (2000), pp. 323-326; De VERDA Y BEAMONTE (2005), pp. 49 y 50; FueYo (2004), p. 574, ello varía en el caso de las relaciones de consumo, puesto que como se indicó, en este ámbito, los derechos de los consumidores son irrenunciables anticipadamente, por lo que una cláusula en contrario será nula y de ningún valor (arts. $4^{\circ}$ y 16 letras $c$, d, e y g LPDC).

142 Della Maggiora; Zárate (2003), p. 8. Por su parte, la comisión redactora de los DCFR (Soft Law), si bien pensó en tratar separadamente estos estatutos, finalmente incorporó reglas conjuntas, con el objeto de no repetir disposiciones. Von Bar et al. (2009), p. 28. Ya en el Anteproyecto de Código Civil y Comercial argentino se unifica el tratamiento (arts. 1708 y siguientes), indicándose en los fundamentos que lo que "se adopta es la unidad del fenómeno de la ilicitud, lo cual no implica la homogeneidad, ya que hay diferencias que subsisten", Fundamentos del Anteproyecto de Código Civil y Comercial de la Nación, disponible en: http://www.lavoz.com.ar/files/FUNDAMENTOS_DEL_ANTEPROYECTO_DE_CODIGO_CIVIL_Y_COMERCIAL_DE_LA_NACION.pdf, revisado el 19.09.2017, p. 216. 
quien lo utilice o disfrute; o bien cuando la víctima desea accionar en contra del fabricante con quien no se ha intervenido de ninguna manera. En este sentido, en nuestro país, la Corte de Apelaciones de Concepción ya había advertido la anacronía de esta distinción: "esta Corte estima erróneo exigir que todas las personas que resultan afectadas por la infracción a la normativa sobre las relaciones del consumo deban ser contratantes, imponiendo una división de la responsabilidad que no se ajusta al carácter lógico y sistemático de nuestro ordenamiento jurídico. De seguirse la tesis del a-quo se produciría una situación no razonable en cuanto, (...) sólo el que adquiere el producto puede invocar las normas sobre protección de los derechos del consumidor, y los restantes deberían invocar una fuente obligacional distinta, (...) todo lo cual es absurdo"143. Con todo, los regímenes unitarios, la discusión acerca del régimen jurídico aplicable a la responsabilidad postcontractual no se presentará, puesto que tendremos únicamente un estatuto que puede resultar procedente.

La situación es distinta en aquellos casos en que se continúa manteniendo la estructura bipartita de la responsabilidad, tal como ocurre con la tradición continental en su gran mayoría -España, Francia, Italia, etc.- e incluso el Reino Unido. Nuestro país se encuentra en este segundo grupo, reconociendo dos regímenes distintos, por lo que cabe preguntarse si los daños postcontrahendo son indemnizables en sede contractual o extracontractual. La relevancia de ello radica en las disímiles reglas aplicables en materias tan importantes como la presunción, prueba y graduación de la culpa; los daños indemnizables; el plazo de prescripción; etc.

\subsection{La situación en el Derecho común}

En una primera etapa la responsabilidad postcontractual fue asimilada a la extracontractual ${ }^{144}$, al considerarse que una vez extinguido el contrato -cumplimiento de las obligaciones-, toda responsabilidad posterior será delictual, dando lugar a deberes y no a obligaciones ${ }^{145}$. Le Tourneau así explica que el deber de seguridad procede en razón de que existe uno más general de no causar daños corporales a otro, sin que corresponda a desfallecimiento contractual, salvo que el contrato verse sobre la persona misma de la víctima ${ }^{146}$.

${ }^{143}$ Corte de Apelaciones de Concepción, rol № 500-2005, de 8 de noviembre de 2007.

144 Le Tourneau (2004), p. 103.

145 Rodríguez (2015), p. 943.

146 Le Tourneau (2004), p. 107. 
En nuestro país, esta tesis ha tenido alguna acogida jurisprudencial, pudiendo citarse como ejemplo la sentencia ya aludida Orellana Acosta con Banco de Crédito e Inversiones (2015) ${ }^{147}$, sobre información a bancos de datos deudas referentes a cuentas cerradas, aunque, recordemos, se declaró prescrita la acción.

Conforme a una segunda línea de opinión, correspondería al estatuto contractual $^{148}$, puesto que deriva del plan prestacional que vincula a las partes $^{149}$, son consecuencia del mismo contrato ${ }^{150}$, y tienen relación directa con sus prestaciones principales ${ }^{151}$. El fundamento de ello radicaría en que la convención sería la causa eficiente de estos deberes ${ }^{152}$, de tal manera que si existen, es porque su eficacia aún no ha cesado. Boetsch Gillet, por su parte, lo justifica en la circunstancia de que se trata de imperativos que "se siguen debiendo precisamente por el hecho de que existió un especial contacto (un contrato) entre las esferas de intereses de acreedor y deudor"153. Respecto de los deberes colaterales en general -dentro de los cuales encontramos a los postcontrahendo-, Bernal Fandiño ha explicado que "siendo parte de una relación jurídica compleja, (...) se deben entender comprendidos en el contenido del contrato" 154 .

Esta tesis también ha tenido recepción en la jurisprudencia nacional, pudiendo citarse como ejemplo, la mencionada causa Fritz Vidal con Banco Santander Chile (2011), la Corte Suprema indicó que la información de una deuda que constaba en un título de crédito vencido, era de tipo contractual, por provenir de la infracción del deber de buena fe derivado del art. 1546 CC $^{155}$.

$1479^{\circ}$ Juzgado Civil de Santiago, rol № C-12291-2011, de 24 de marzo de 2015; Corte de Apelaciones de Santiago, rol No 10784-2015, de 25 de julio de 2016, se declara inadmisible el recurso de casación y Corte Suprema, rol No 62204-2016, de 5 de diciembre de 2016.

148 Benítez (2013); Facco (2009), p. 3; Boetsch (2015), p. 131; Farías (2014), p. 2; Martín (2004), p. 3114; Rezzónico (1999), p. 530; Varacall y Picasso (1994), p. 236.Corte Suprema, rol No 430-2010,

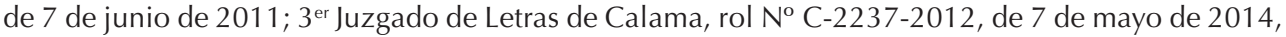
finalmente se celebró transacción, Corte de Apelaciones de Antofagasta, rol № 626-2014, de 22 de diciembre de 2014.

149 Benítez (2013).

150 Varacalli y Picasso (1994), p. 235.

151 Solarte (2004), p. 313.

152 Farías (2014), p. 5; Varacalli y Picasso (1994), p. 236.

153 BOETSCH (2015), p. 131.

154 Bernal (2013), p. 57.

155 Corte Suprema, rol No 137-2010, de 4 de julio de 2011. Otras sentencias que también le han otorgado el carácter de contractual: Corte Suprema, rol No 430-2010, de 7 de junio de 2011; 
Por su parte, Celis Rodríguez a propósito de un caso en que un Banco informó a la SBIF una deuda ya pagada, estimó que no se trataría de responsabilidad extracontractual, por cuanto el acto que provocó el daño no guarda relación o sólo externa con el contrato y su ejecución, siendo uno de sus requisitos de la relación de causalidad ${ }^{156}$.

Leiva Fernández, en tanto, distingue según la fuente originaria. Así, si tiene por causa la violación de un deber legal o implícito del contrato que frustre la ventaja esperable, será contractual157. En los demás casos, podrá ser calificada de extracontractual, como ocurriría con aquel consumidor que desprestigia injustificadamente a un proveedor para que otros sujetos no contraten con él ${ }^{158}$.

\subsection{La situación en el Derecho del Consumidor}

El panorama de la responsabilidad civil en la LPDC no es muy feliz, en el sentido de que se trata de una realidad consagrada, mas no regulada ${ }^{159}$. La situación se agrava, si se considera que tampoco se indica el régimen supletorio al cual se debe recurrir en caso de silencio normativo -que en este caso es bastante amplio-, y el cual por lo demás se encuentra sujeto a la respuesta que se otorgue respecto de su eventual accesoriedad respecto de la acción contravencional. En efecto, una de las más importantes y antiguas discusiones que han tenido lugar a partir de la entrada en vigencia de la LPDC, dice relación con la determinación de si las acciones civiles son dependientes o bien autónomas de la condena infraccional. Si bien, esta problemática tiene un importante asidero en ciertas normas contenidas en la regulación de los Juzgados de Policía Local-tribunales que normalmente conocen de estos asuntos (arts. $9^{\circ}$ y 14 Ley $N^{0} 18.287$ ) ${ }^{160}$, la redacción de la propia LPDC también daría pie para que se persevere en la discusión (por ejemplo sus arts. $3^{\circ}$ y 50 ).

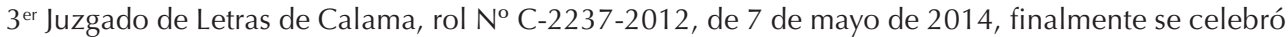
transacción, Corte de Apelaciones de Antofagasta, rol № 626-2014, de 22 de diciembre de 2014.

156 Celis (2009), p. 761.

157 Leiva (2002).

158 LeIva (2002).

159 Para LóPEZ (2009), pp. 1060 y 1061, la responsabilidad civil por productos, no puede ser calificada ni de contractual ni extracontractual, sino que es legal especial (Ley № 19.496).

160 Un análisis de esta problemática: GuerRero (2008), pp. 433-453; IsLeR (2017), pp. 111-167.
} 
Con todo, de aceptarse la primera tesis ${ }^{161}$, la responsabilidad civil, al provenir de la infracción, siempre tendrá el carácter de extracontractual (art. $2314 \mathrm{CC})^{162}$, por lo que no se presentará la duda acerca del estatuto aplicable. No obstante, la doctrina correcta es la segunda, esto es, se trata de estatutos independientes entre sí163, de tal manera que se debe recurrir al Derecho Común como régimen supletorio, y en tal sentido, se tratará de responsabilidad contractual. A mayor abundamiento, cabe agregar que si en esta sede se suele romper el principio del efecto relativo de los contratos ${ }^{164}$ cuando no ha existido vínculo previo alguno con el proveedor-por ejemplo la acción de un consumidor en contra del fabricante-, con mayor razón se aplicará dicho estatuto, si ello ha ocurrido.

161 Valdés Rodríguez con Delgado Figueroa, $1^{\text {er }}$ Juzgado de Policía Local de Santiago, rol № 38363-2009, de 26 de julio de 2010; Gutiérrez con Homecenter, $1^{\text {er }}$ Juzgado de Policía Local de Viña del Mar, rol № 8306-2007, de 25 de febrero de 2008; Canahuate con Sociedad Szerecz y Molina

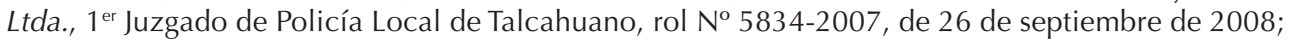

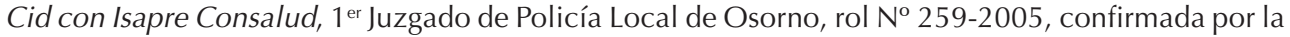
Corte de Apelaciones de Valdivia, rol № 125-2006, de 5 de mayo de 2006; Pérez Vera con Calzados

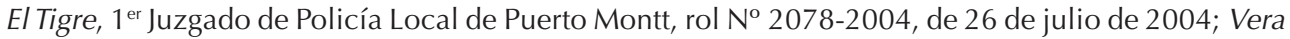
Pincol con Electrónica del Sur, Juzgado de Policía Local de Coyhaique, rol № 29.863-2009, de 18 de agosto de 2009; Martínez con Hites S.A., $1^{\text {er }}$ Juzgado de Policía Local de Santiago, rol № $14905-$ 2010, de 29 de noviembre de 2010; Meléndez Arteaga con Óptica Ver Bien Limitada, $1^{\text {er }}$ Juzgado de Policía Local de Santiago, rol №5760-2010, de 18 de enero de 2011; Bravo Cáceres con Ind

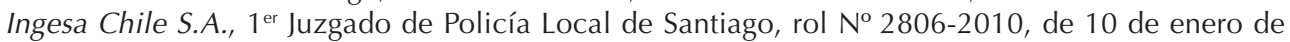
2011; Vilches Cruz con Comercial Electro South Ltda., $4^{\circ}$ Juzgado de Policía Local de Santiago, rol № 732-3-2010, de 21 de octubre de 2010; González Olivares con Inmobiliaria PY S.A., Corte de Apelaciones de La Serena, rol № 223-2009, de 28 de diciembre de 2009; Sernac con Compañía de Telecomunicaciones de Chile $1^{\text {er }}$ Juzgado de Policía Local de Pudahuel, rol № 5278-2006, de 28 de diciembre de 2007, confirmada en este punto por la Corte de Apelaciones de Santiago, rol № 904-2008, de 19 de marzo de 2008.

162 Aimone (2013), p. 115; Rodríguez (2006), p. 120. Jurisprudencia: Movimiento de Tierra José Hormazábal Vidal EIRL con Komatsu Cummins Chile Arrienda Ltda., Juzgado de Policía Local de Quilicura, rol № 82648-2-2012, de 11 de febrero de 2013; Valdés Rodríguez con Delgado Figueroa,

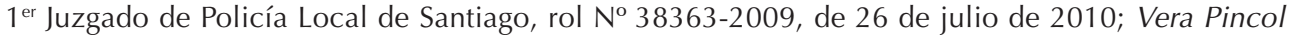
con Electrónica del Sur, Juzgado de Policía Local de Coyhaique, rol № 29863-2009, de 18 de agosto

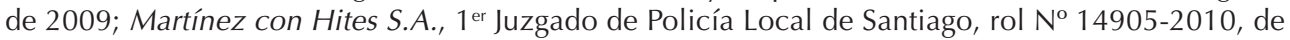
29 de noviembre de 2010; Sernac y Negrete Toro con Derco Autos S.A., Juzgado de Policía Local de Quilicura, rol No 33622-2006, de 27 de octubre de 2006, confirmada por la Corte de Apelaciones de Santiago, rol № 6923-2006, de 11 de abril de 2007.

163 Baraona (2010); Baraona (2014), p. 394; Barrientos y Contardo (2013), p. 582; Cárdenas (1999), pp. 69-71; Corral (2013), p. 18; Cortez (2004), p. 26.

164 Se debe romper si contraría la justicia: Амат (2003), p. 1286. Quien contrata, también lo hace para sí (deber primario) y en provecho de cualquiera que tenga un interés legítimo en la cosa (deber secundario): АMAт (2003), p. 1286. Acerca del efecto expansivo de los contratos: López (1976), pp. 79-81; ReZZÓNICO (1999), p. 246. 
Sin perjuicio de lo anterior, se debe tener presente que al encontrarnos frente a supuestos en los cuales se ha celebrado un contrato, es que se formará un concurso entre la responsabilidad contractual originada en su incumplimiento (autónoma), y la extracontractual derivada de la infracción del art. 12 LPDC. En estos casos, es el legitimado activo quien debe optar por un régimen u otro ${ }^{165}$, pero hecha la opción, la relación se regulará íntegramente por el estatuto escogido ${ }^{166}$.

Esta misma solución ya había sido planteada antes a propósito de la responsabilidad precontractual. En efecto, la profesora Zuloaga Ríos sostiene que ella presenta una naturaleza distinta de la contractual y extracontractual, desde que, si bien presenta características de ambas, se las diferencia en otras ${ }^{167}$. En estos casos, se debe aplicar el régimen que sea más favorable al perjudicado -incluso combinando los regímenes-, de acuerdo con los imperativos de la buena fe, la justicia y la equidad ${ }^{168}$.

\section{Conclusiones}

A partir de la reformulación y nuevo estudio de la responsabilidad civil, es que ha cobrado fuerza la preocupación por la resarcibilidad de los daños en la etapa postcontractual, esto es, aquella que se inicia una vez que se han extinguido las obligaciones principales del contrato. En Chile, si bien la doctrina que se ha pronunciado en favor de la procedencia de una responsabilidad de este tipo no es abundante aún, sí se puede reconocer una creciente preocupación por su tratamiento, lo cual además se evidencia en la paulatina apertura de la jurisprudencia a reconocerla. En la esfera del Derecho del Consumo, ella resulta plenamente procedente, puesto que su ámbito de aplicación se determina por la relación de consumo, esto es, un vínculo jurídico que surge entre un proveedor y un consumidor, el cual no se extingue por el mero cumplimiento de las obligaciones principales del contrato.

Por otra parte, los deberes postcontrahendo pueden tener origen tanto en la convención como en una norma jurídica, sea que se los mencione de

165 Barrientos (2010), p. 628; Corral (2013), p. 34; Isler (2017), pp. 151-153; Zelaya (1999), p. 247. Según unos, el concurso procede sólo cuando concurren responsabilidad penal y civil (ALESSANDRI (1943), pp. 84-92; ALESSANDRI et al. (1942), p. 911); para otros procede también respecto de la responsabilidad contravencional [Corral (2013), p. 32]. Según Larroucau (2012), pp. 461-479, el juez puede inclinarse por uno de los regímenes.

166 CORRAL (2013), p. 34.

167 Zuloaga (2008), pp. 124-127.

168 Zuloaga (2008), p. 140. 
manera explícita, o que se deriven de la consagración general de la buena fe, como elemento integrador del contrato.

Si bien, en el Derecho Común, el régimen jurídico que le resulta aplicable es el contractual, en sede de protección de los derechos de los consumidores, se formará un concurso entre la responsabilidad civil autónoma (contractual) y la accesoria a la contravencional (extracontractual), en el cual el legitimado activo puede optar por una u otra. Ello determinará los plazos de prescripción que resulten procedentes.

\section{BiBLIOGRAFíA CITADA}

Abeliuk Manasevich, René (2008): Las obligaciones (Santiago, Editorial Jurídica de Chile), Tomo 2.

Aimone Gibson, Enrique (2013): Protección de Derechos del Consumidor (Santiago, Thomson Reuters).

Alessandri Rodríguez, Arturo (1939): Teoría de las Obligaciones (Zamorano y Caperán).

AlesSANDri Rodríguez, Arturo (1943): La responsabilidad extracontractual en el Derecho Civil chileno (Santiago, Imprenta Universitaria).

Alessandri Rodríguez, Arturo; Somarriva Undurraga, Manuel y Vodanovic H., Antonio (1941): Curso de Derecho Civil (Santiago, Nascimento), Tomo 3.

Alessandri Rodríguez, Arturo; Somarriva Undurraga, Manuel y Vodanovic H., Antonio (1942): Curso de Derecho Civil (Santiago, Nascimento), Tomo 4.

Alessandri Rodríguez, Arturo; Somarriva Undurraga, Manuel y Vodanovic H., Antonio (1971): Curso de Derecho Civil (Santiago, Nascimento).

Alessandri Rodríguez, Arturo; Somarriva Undurraga, Manuel y Vodanovic H., Antonio (2004): Tratado de las obligaciones (Santiago, Editorial Jurídica de Chile).

Amat Lları, María Eulalia (2003): "La teoría de la relatividad del contrato y sus excepciones", en: Cabanillas, Antonio (coordinador), Estudios en Homenaje al profesor Luis Díez-Picazo (Madrid, Civitas), pp. 1275-1289.

BANFi Del Río, Cristián (2000): "La asimilación de la culpa grave al dolo en la responsabilidad contractual en Chile", en: Revista Chilena de Derecho (Vol. 27, No 2), pp. 291-330.

Baraona GonzÁlez, Jorge (2010): "Superposición de los regímenes de responsabilidad en el ámbito del consumo. ¿Responsabilidad infraccional, extracontractual, contractual?", en: XI Seminario de Actualización en Derecho de Daños, UAndes, de 23 de noviembre de 2010. 
BARAONA González, Jorge (2014): “La regulación contenida en la Ley Nº 19.496 sobre Protección de los Derechos de los Consumidores y las reglas del Código Civil y Comercial sobre contratos: un marco comparativo", en: Revista Chilena de Derecho (Vol. 41, No 2), pp. 381-408.

BARCIA LeHMANN, Rodrigo (2006): "La asimilación de la culpa grave al dolo desde una perspectiva objetiva del Derecho de los Contratos. Primera parte", en: Revista lus et Praxis (Vol. 12, № 2), pp. 75-95.

Barcia LehmanN, Rodrigo (2012): "Estudio sobre la prescripción y caducidad en el Derecho del Consumo", en: Revista Chilena de Derecho Privado (No 19), pp. 115-163.

BarCia LehmanN, Rodrigo (2013): "Artículo 26 LPDC", en: De la Maza, Íñigo y Pizarro, Carlos (editores), La protección de los derechos de los consumidores (Santiago, Editorial Thomson Reuters), pp. 607-648.

Barrientos Camus, Francisca (2010): "Función del artículo 23 como fuente ambigua de responsabilidad en la Ley de Protección al Consumidor. Alguna jurisprudencia reciente", en: Pizarro, Carlos (coordinador), Estudios de Derecho Civil IV (Santiago, LegalPublishing), pp. 625-642.

Barrientos Camus, Francisca (2011): "Comentario de jurisprudencia", en: Revista Chilena de Derecho Privado (No 17), pp. 265-275.

Barrientos Camus, Francisca y Contardo González, Juan Ignacio (2013): “Art. 23 inc. 1", en: Pizarro, Carlos y De la Maza, Íñigo (directores), La protección de los derechos de los consumidores (Santiago, Thomson Reuters), pp. 556-582.

Barros Bourie, Enrique (1999): "Límites de los derechos subjetivos privados. Introducción a la doctrina del abuso del derecho", en: Revista Derecho y Humanidades ( $\left.\mathrm{N}^{\circ} 7\right)$, pp. 11-37.

BARros Bourie, Enrique (2014): Tratado de responsabilidad extracontractual (Santiago, Editorial Jurídica de Chile).

Benítez, Nicolás (2013): "Responsabilidad postcontractual y deberes secundarios de conducta", en: Revista Jurídica de Daños ( $\left.N^{\circ} 7\right)$. Disponible en: http:// www.ijeditores.com.ar/articulos.php?idarticulo=66876\&print $=2$ [visitado el 21/12/2017].

Bernal Fandiño, Mariana (2013): "La naturaleza jurídica de la responsabilidad civil derivada de la inobservancia de los deberes colaterales de conducta", en: Revista Universitas ( $\left.{ }^{\circ} 126\right)$, pp. 39-64.

BetTI, Emilio (1969): Teoría general de las obligaciones (Madrid, Revista de Derecho Privado), Tomo 1.

BoetsCh Gillet, Cristián (2015): La buena fe contractual (Santiago, Ediciones UC). 
Cárdenas Bustamante, Mario (1999): "Análisis jurídico de la Ley de Protección al Consumidor", en: Revista de Derecho (Vol. X), pp. 69-74.

Celis Rodríguez, Rubén (2009): "Informe en Derecho", en: Tavolari, Raúl (director), Doctrinas esenciales. Responsabilidad extracontractual (Santiago, Editorial Jurídica de Chile), pp. 755-768.

Conde Marín, Emilia (2007): La buena fe en el contrato de trabajo. Un estudio de la buena fe como elemento de integración del contrato de trabajo (Madrid, La Ley).

Contreras Aburto, Luis (2009a): "Algunos aspectos de la prescripción extintiva", en: Tavolari, Raúl (director), Doctrinas esenciales. Derecho Civil. Obligaciones (Santiago, Thomson Reuters PuntoLex), Tomo 2, pp. 541- 594.

Corbettı, Ariel I. (2010): "La protección del más débil como origen de un nuevo Derecho de los Contratos", en: Martinic, María y Tapia, Mauricio (directores), Sesquicentenario del Código Civil de Andrés Bello (Santiago, Abeledo-Perrot. LegalPublishing), pp. 663-684.

Corral TalCIANI, Hernán (1999): "Ley de protección al consumidor y responsabilidad civil por productos y servicios defectuosos", en: Corral, Hernán (editor), Derecho del Consumo y protección al consumidor: Estudios sobre la Ley No 19.496 y las principales tendencias extranjeras (Santiago, Universidad de los Andes), pp. 163-211.

Corral Talciani, Hernán (2011): Responsabilidad por productos defectuosos (Santiago, Abeledo Perrot).

Corral Talcian, Hernán (2013): Lecciones de responsabilidad civil extracontractual (Santiago, Thomson Reuters).

CORTEZ MATCOVICH, Gonzalo (2004): El nuevo procedimiento regulado en la Ley $N^{\circ} 19.496$ (Santiago, Lexis Nexis).

De la Maza Gazmurı, Íñigo (2012a): "El régimen de los cumplimientos defectuosos en la compraventa", en: Revista Chilena de Derecho (Vol. 39, № 3), pp. 629-663.

De la Maza Gazmurı, Íñigo (2012b): “Configuración de la obligación de entregar a través de la autonomía privada: derechos de terceros", en: Revista de Derecho, Pontificia Universidad Católica de Valparaíso (XXXIX), pp. 95-114.

De la Maza Gazmurı, Íñigo (2013): "Contratos especiales", en: Revista Chilena de Derecho Privado (№ 20), pp. 235-240.

De Verda y Beamonte, José Ramón (2005): "Las cláusulas de exoneración y limitación de responsabilidad en el derecho español", en: Revista Chilena de Derecho Privado (No 4), pp. 33-80. 
Enneccerus, Ludwig (1948): Tratado de Derecho Civil. Parte General (Buenos Aires, Bosch), Tomo 2, Volumen II.

FACCO, Javier Humberto (2009): "Ultractividad de ciertos efectos contractuales", en: Revista de Responsabilidad Civil y Seguros ID (Año 11, № VII), pp. 16-27.

FaríAs Soto, Javiera (2014): Breves notas sobre la responsabilidad postcontractual en Chile, particularmente en materia de consumo (en prensa).

FerNÁNDEZ Fredes, Francisco (1998): "Nueva Ley del Consumidor: innovaciones y limitaciones", en: Revista Perspectivas en Política, Economía y Gestión (No 2), pp. 107-126.

Fueyo Lanerı, Fernando (1958): Derecho Civil (Santiago, Roberts y Cía. Ltda.), Tomo 4, Volumen I.

Fueyo LANerI, Fernando (2004): Cumplimiento e incumplimiento de las obligaciones (Santiago, Editorial Jurídica).

GHERSI, Carlos (1999): "Las cláusulas abusivas en los contratos de compraventa de automotores por ahorro previo", en: Ghersi, Carlos (director), Cláusulas abusivas I (Rosario, Editorial Juris), pp. 79-101.

Gómez Pomar, Fernando (2007): "El incumplimiento contractual en Derecho español". Disponible en: http://www.indret.com/pdf/466_es.pdf [visitado el 21.12.2017].

GonZÁlez CAStillo, Joel (2011): "Las cláusulas limitativas, agravantes o exonerativas de responsabilidad en materia contractual. Validez y Límites", en: Revista Chilena de Derecho (Vol. 38, № 1), pp. 89-100.

Guerrero Becar, José Luis (2008): "La distinción entre contravención infraccional e incumplimiento contractual", en: Guzmán, Alejandro (editor), Colección de estudios de Derecho Civil en homenaje a la profesora Inés Pardo de Carvallo (Valparaíso, Ediciones Universitarias de Valparaíso), pp. 433-453.

GuZmán Brito, Alejandro (2002): "La buena fe en el Código Civil de Chile", en: Revista Chilena de Derecho (Vol 29, № 1), pp. 11-23.

IrUReta Uriarte, Pedro (2011): "Vigencia del principio de la buena fe en el derecho del trabajo chileno", en: Revista lus et Praxis (Año 17, $\mathrm{N}^{\circ} 2$ ), pp. 133- 188.

IsLer Soto, Erika Marlene (2010a): "La relación de consumo como criterio de aplicabilidad del derecho de protección del consumidor", en: Revista de Derecho de la Empresa (No 23), pp. 97-126. 
Isler Soto, Erika Marlene (2010b): "Comentario de Sentencia sobre Responsabilidad Civil del Proveedor", en: Revista de Derecho (Vol. XXIII, $\mathrm{N}^{\mathrm{o}}$ 1), pp. 333-338.

Isler Soto, Erika (2014): "Comentario de sentencia sobre el concepto de consumidor", en: Revista Chilena de Derecho y Ciencia Política (Vol. 5, No 1), pp. 151-165.

Isler Soto, Erika (2017): Prescripción extintiva en el Derecho del Consumo (Santiago, Rubicón).

Jara Amigo, Rony (1999): "Ámbito de aplicación de la Ley chilena de protección al consumidor: inclusiones y exclusiones", en: Corral, Hernán (editor), Derecho del consumo y protección al consumidor. Estudios sobre la Ley $N^{\circ} 19.496$ y las principales tendencias extranjeras. Cuadernos de Extensión Jurídica 3. (Santiago, UAndes), pp. 47-74.

JARA AmIGO, Rony (2006): "Ámbito de aplicación de la Ley chilena de protección al consumidor: Aplicación de la Ley $\mathrm{N}^{\circ} 19.496$ y modificaciones de la Ley № 19.955", en: Cuadernos de Extensión (№ 12), pp. 21-58.

Larenz, Karl (1958-1959): Derecho de Obligaciones (Madrid, Editorial Revista de Derecho Privado), Tomo 1.

LarRouCAu Torres, Jorge (2012): "La opción de responsabilidad civil como un acertijo procesal", en: Elorriaga, Fabián (coordinador), Estudios de Derecho Civil VII (Santiago, Thomson Reuters), pp. 461-479.

Le Tourneau, Philippe (2004): La responsabilidad civil (Colombia, Editorial Legis).

LeIva FeRnÁndez, Luis (2002): La responsabilidad postcontractual (Buenos Aires, Thomson Reuters).

López Santa María, Jorge (1976): "Problemas actuales en el Derecho de los Contratos", en: Estudios de Derecho Civil en memoria del profesor Victorio Pescio (Santiago, Universidad de Chile), pp. 29-108.

López Santa María, Jorge (2005): Los contratos. Parte General (Santiago, Editorial Jurídica de Chile), Tomo 2.

López Santa María, Jorge (2009): "La responsabilidad civil por productos", en: Tavolari, Raúl (director), Doctrinas Esenciales. Derecho civil. Responsabilidad Extracontractual (Santiago, Thomson Reuters), pp. 1043-1085.

LORENZETTI, Ricardo Luis (sin año): Teoría sistémica del contrato. Disponible en: http://seer.ufrgs.br/index.php/ppgdir/article/dowload/52835/32773 [visitado el 20.09.2017]. 
Martín Meléndez, María Teresa (2004): "Fundamento de la atribución del uso de la vivienda familiar al esposo no titular y de su privación al titular en los casos de separación, divorcio y nulidad de matrimonio", en: González, José y Méndez, Fernando (coordinadores), Libro Homenaje al profesor Manuel Albaladejo García (Murcia, Universidad de Murcia), Vol. 1, pp. 3099-3117.

Momberg URibe, Rodrigo (2004): "Ámbito de Aplicación de la Ley No 19.496 sobre Protección de los Derechos de los Consumidores", en: Revista de Derecho, Universidad Austral de Chile (Vol. XVII), pp. 41-62.

Momberg URibe, Rodrigo (2013a): "Art. 1 № 1", en: De la Maza, Íñigo y Pizarro, Carlos (editores), La protección de los derechos de los consumidores (Santiago, Thomson Reuters), pp. 3-16.

Momberg Uribe, Rodrigo (2013b): "Art. 2 LPDC", en: De la Maza, Íñigo y Pizarro, Carlos (editores), La protección de los derechos de los consumidores (Santiago, Thomson Reuters), pp. 66-76.

Momberg URibe, Rodrigo(2013c): "Art. 2 bis" en: De la Maza, Íñigo y Pizarro, Carlos (editores), La protección de los derechos de los consumidores (Santiago, Thomson Reuters), pp. 77-83.

Momberg Uribe, Rodrigo y Pizarro Wilson, Carlos (2013): “Artículo 16 g)", en: De la Maza, Íñigo y Pizarro, Carlos (editores), La protección de los derechos de los consumidores (Santiago, Editorial Thomson Reuters), pp. 340-351.

Monroy C., Daniel A. (2016): "Reglas supletivas 'sancionatorias' en el derecho de contratos colombiano: el caso del contrato de transporte", en: Revista de Derecho Privado Universidad del Externado de Colombia ( $\left.\mathrm{N}^{\circ} 30\right)$, pp. 221-254.

Monsalve Caballero, Vladimir (2008): "La buena fe como fundamento de los deberes precontractuales de conducta: una doctrina europea en construcción", en: Revista de Derecho Universidad del Norte ( $\left.N^{\circ} 30\right)$, pp. 30-74.

NeUberGer, David (2014): The impact of pre-and post-contractual conduct on contractual interpretation. Disponible en: https://www.eiseverywhere.com/ file_uploads/d287ff445a9a9207cb6dd88b475bac2f_P3-LordNeuberger.pdf [visitado el 21.12.2017].

Palermo, Antonio (1969): L'Assicurazione di Responsabilitá Civile (Piacenza, Editrice La Tribuna).

Peñailillo Arévalo, Daniel (1996): "Los elementos subjetivos en las instituciones y conceptos del Derecho Civil y su establecimiento", en: Instituciones modernas de Derecho Civil. Homenaje al profesor Fernando Fueyo Laneri (Santiago, Editorial Jurídica ConoSur Ltda.), pp. 34-43. 
Peñallillo Arévalo, Daniel (2007): "La reforma del Código Civil francés en derecho de obligaciones y el Código Civil chileno", en: A.A. V.V., Reformas en el Derecho Civil francés y perspectivas para el Derecho chileno (Santiago, UDD), pp. 113-137.

PICASSO, Sebastián (2007): "La teoría general del contrato en los proyectos de reforma del Código Civil argentino", en: A.A. V.V., Reformas en el Derecho Civil francés y perspectivas para el Derecho chileno (Santiago, UDD), pp.73-87.

Pinochet Olave, Ruperto (2011): "Delimitación material del Derecho del Consumo: Evolución de la noción de consumidor en la doctrina nacional", en: Zegers, Matías; Alcalde, Jaime; Goldenberg, Juan y Ríos, Roberto (editores), Estudios de Derecho Comercial (Santiago, Abeledo Perrot) pp. 343-367.

Reveco URzúA, Ricardo (2010): "Una aproximación al conflicto de interés", en: Martinic, María y Tapia, Mauricio (directores), Sesquicentenario del Código Civil de Andrés Bello (Santiago, Abeleto-Perrot. LegalPublishing), pp. 749-788.

RezzónICO, Juan Carlos (1999): Principios fundamentales de los contratos (Buenos Aires, Astrea).

Rodríguez Grez, Pablo (2008): Extinción no convencional de las obligaciones (Santiago de Chile, Editorial Jurídica de Chile), volumen 2.

Rodríguez PINTO, María Sara (2006): "Prestación de servicios y responsabilidad civil en la Ley sobre Protección de los Derechos de los Consumidores", en: Cuadernos de Extensión Jurídica (No 12), pp. 111-127.

Rodríguez Russo, Jorge (2015): “Contrato y responsabilidad civil. A propósito de la responsabilidad postcontractual y su disciplina jurídica", en: Anuario de Derecho Civil Uruguayo (№ 45), pp. 929-945.

Ruiz Tagle-Vial, Carlos (2010): Curso de Derecho Económico (Santiago, Librotecnia).

SAAVEDRA, Francisco Javier (1996): "El principio de la buena fe", en: Instituciones modernas de Derecho Civil. Homenaje al profesor Fernando Fueyo Laneri (Santiago, Editorial Jurídica ConoSur Ltda.), pp. 357-373.

Sierra Herrero, Alfredo (2014): "La cláusula de no competencia post-contractual en el contrato de trabajo", en: Revista lus et Praxis (Año 20, No 2), pp. 109-156.

Solarte Rodríguez, Arturo (2004): "La buena fe contractual y los deberes secundarios de conducta", en: Universitas (№ 108), pp. 281-315.

Staub, Hermann (1913): Die positiven Vertragsverletzungen, $2^{a}$ edición (Berlin, Guttentag Verlagsbuchhandlung). 
Tallos del Río, Jesús (2017): "La doctrina del Tribunal Superior de Justicia de Cataluña sobre los pactos laborales de no competencia postcontractual", en: Labor 1/201. Disponible en: https://www.upf.edu/documents/3885005/8337152/Tallos_editado.pdf/151b8fed-d054-ad46-bdf61d5189aa686e [visitado el 21.12.2017].

UGARTE VIAL, Jorge (2012): "Fundamentos y acciones para la aplicación del levantamiento del velo en Chile", en: Revista Chilena de Derecho (Vol. 39, NN3), pp. 699-723.

VAracallı, Daniel C. y Picasso, Sebastián (1994): "Responsabilidad precontractual y postcontractual", en: Lecciones y Ensayos ( ${ }^{\circ} 60$ y 61), pp. 209-239.

Vattier Fuenzalida, Carlos (2001): "Responsabilidad contractual y extracontractual en el comercio electrónico", en: Revista de Contratación Electrónica ( No 18), pp. 67-90.

Vera García, Rodrigo Hernán (2014): "Los deberes de lealtad y fidelidad y sus límites en el contrato de trabajo", en: Revista de Derecho, Universidad Católica de la Santísima Concepción (N 30), pp. 81-100.

VIDAl Olivares, Álvaro (2009): "La noción de incumplimiento esencial en el Código Civil", en: Revista de Derecho, Pontificia Universidad Católica de Valparaíso ( ${ }^{\circ}$ XXXII), pp. 221-258.

Zelaya Etchegaray, Pedro (1999): "El cúmulo u opción de responsabilidades en la nueva ley de protección al consumidor", en: Cuadernos de Extensión (No 3), pp. 213-250.

Zuloaga Ríos, Isabel Margarita (2008): Teoría de la responsabilidad precontractual. Aplicaciones en la formación del consentimiento de los contratos (Santiago, LegalPublishing).

Zuloaga Ríos, Isabel Margarita (2015): "Formation III: Arts. 2.1.15-2.1.16. Negotiations", en: Voguenauer, Stefan y Kleinheisterkamp, Jan (editores), Commentary on the Unidroit Principles of International Commercial Contracts, 2 Edition (Oxford, Oxford University Press), pp. 342-370.

\section{Normativa CITADA}

Código Civil, Chile.

Ley No 19.496, Chile, D.O. 7.03.1997.

Ley $N^{0}$ 18.287, Chile, D.O. 7.02.1984.

Ley No 19.628, Chile, D.O. 28.08.1999.

Bürgerliches Gesetzbuch, Alemania, 18.08.1896.

Ley N $N^{\circ} 1.480$ del Consumidor, Colombia, 12.10.2011. 
Ley General para la Defensa de los Consumidores y Usuarios y otras leyes complementarias, Real Decreto Legislativo 1/2007, España.

Ley No 1334 de Defensa del Consumidor y Usuario, Paraguay.

Ley N N 29.571, Código de Protección y Defensa del Consumidor, Perú.

Ley $\mathrm{N}^{\circ} 45$, que dicta normas sobre Protección al Consumidor y Defensa de la

Competencia y otra disposición, Panamá.

Ley No 24/96 de Defensa del Consumidor, Portugal.

Fundamentos del Anteproyecto de Código Civil y Comercial de la Nación. Disponible en: http://www.lavoz.com.ar/files/FUN].DAMENTOS_DEL_ ANTEPROYECTO_DE_CODIGO_CIVIL_Y_COMERCIAL_DE_LA_NACION. pdf [visitado el 19/09/2017].

Principios Unidroit sobre contratos comerciales internacionales, 2016.

Draft Common Frame of Reference, Proyecto de un Marco Común de Referencia. Proyecto de ley, Boletín No 9.369-03.

\section{JURISPRUDENCIA CITADA}

Sernac con Farmacias Ahumada S.A. (2016): Corte Suprema, rol № 1540-2015, de 7 de marzo de 2016, acoge casación Corte de Apelaciones de Santiago, rol № 109-2014, de 17 de noviembre de 2014, que revoca $1^{\circ} \mathrm{JL}$ de Santiago, rol No 37607-2009, de 10 de octubre de 2013.

Orellana Acosta con Banco de Crédito e Inversiones (2015): $9^{\circ}$ Juzgado Civil de Santiago, rol No C-12291-2011, de 24 de marzo de 2015, Corte de Apelaciones de Santiago, rol No 10784-2015, de 25 de julio de 2016, se declara inadmisible el recurso de casación, Corte Suprema, rol No 62204-2016, de 5 de diciembre de 2016.

Inversiones Clarkson y Compañía Limitada con Donoso Caamaño (2014): Corte Suprema, rol № 2073-2013, de 29 de mayo de 2014, cita online: $\mathrm{CL} / J U R / 2748 / 2014$.

Vera Videla con Salcobrand (2015): Corte Suprema, rol № 10546-2015, de 30 de septiembre de 2015, acoge recurso de queja interpuesto respecto de la Corte de Apelaciones de Valparaíso, rol № 315-2015, de 5 de agosto de 2015, cita online: CL/JUR/5959/2015; 108215.

AGL Comercial Limitada con Corporación Nacional del Cobre de Chile

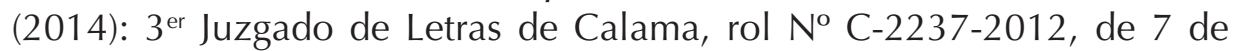
mayo de 2014, finalmente se celebró transacción, Corte de Apelaciones de Antofagasta, rol № 626-2014, de 22 de diciembre de 2014. 
Cavagnaro Hukdhs, Óscar Manuel con Johnsons S.A. (2013): Corte de Apelaciones de Valparaíso, rol No 473-2013, de 2 de diciembre de 2013.

Sernac y Rivera con Administradora de Supermercados Hiper Limitada (2013):

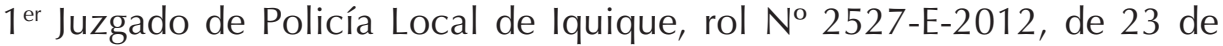
enero de 2013.

Movimiento de Tierra José Hormazábal Vidal EIRL con Komatsu Cummins Chile Arrienda Ltda. (2013): Juzgado de Policía Local de Quilicura, rol No 82648-2-2012, de 11 de febrero de 2013.

Halabi Dial con Easy S.A. (2012): Juzgado de Policía Local de Peñalolén, rol № 29126-2-2010, de 12 de diciembre de 2012.

Sernac con Hipermercado Vespucio Maipú S.A. (2012): $1^{\text {er }}$ Juzgado de Policía Local de Maipú, rol No 6340-2010, de 31 de enero de 2012, confirmada por la Corte de Apelaciones de Santiago, rol № 605-2012, de 23 de enero de 2013.

Sernac con Cencosud Supermercados S.A. (2012): Juzgado de Policía Local de La Cisterna, rol No 33324-2-2011, de 25 de mayo de 2012, confirmada por la Corte de Apelaciones de San Miguel, rol No 1325-2012, de 3 de enero de 2013.

Jiménez Mira con Armijo Cerda (2011): Corte Suprema (Recurso de Casación), rol № 1872-2010, de 29 de diciembre de 2011.

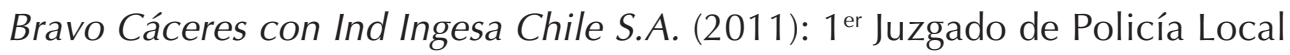
de Santiago, rol No 2806-2010, de 10 de enero de 2011.

Fritz Vidal con Banco Santander Chile (2011): Corte Suprema (Recurso de Casación), rol No 137-2010, de 4 de julio de 2011, cita online: $\mathrm{CL} / \mathrm{JUR} / 10081 / 2011$.

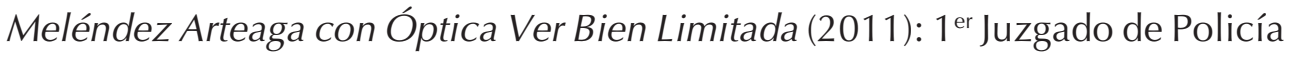
Local de Santiago, rol No 5.760-2010, de 18 de enero de 2011.

Palacios Krogh con Stone Cereceda (2011): Corte Suprema (Recurso de Casación), rol No 430-2010, de 7 de junio de 2011, cita online: CL/JUR/10077/2011.

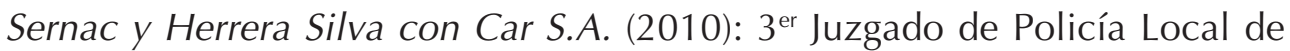
Santiago, rol No 23618-DIO-2008, de 18 de marzo de 2010, confirmada por la Corte de Apelaciones de Santiago, rol № 1617-2010, de 28 de julio de 2010.

Cabrera Arenas con Entel PCS Telecomunicaciones S.A. (2010): $4^{\circ}$ Juzgado de Policía Local de Santiago, rol No 2228-5-2010, de 19 de octubre de 2010. Vilches Cruz con Comercial Electro South Ltda. (2010): $4^{\circ}$ Juzgado de Policía Local de Santiago, rol No 732-3-2010, de 21 de octubre de 2010. 
Valdés Rodríguez con Delgado Figueroa (2010): $1^{\text {er }}$ Juzgado de Policía Local de Santiago, rol № 38363-2009, de 26 de julio de 2010.

Martínez con Hites S.A. (2010): $1^{\text {er }}$ Juzgado de Policía Local de Santiago, rol № 14905-2010, de 29 de noviembre de 2010.

Sernac y Saldías Urrutia con Administradora de Créditos Comerciales Presto Ltda. (2009): Juzgado de Policía Local de Huechuraba, rol No 109890-6, de 29 de diciembre de 2009.

Vera Pincol con Electrónica del Sur (2009): Juzgado de Policía Local de Coyhaique, rol No 29863-2009, de 18 de agosto de 2009.

González Olivares con Inmobiliaria PY S.A. (2009): Corte de Apelaciones de La Serena, rol No 223-2009, de 28 de diciembre de 2009.

Sernac y Quiroga Cavieres con Cencosud Supermercados S.A. (2009): Juzgado de Policía Local de Quilicura, rol № 10833-3-2008, de 26 de agosto de 2009.

Fuentes Gajardo con Supermercado Lider San Bernardo (2009): $2^{\circ}$ Juzgado de Policía Local de San Bernardo, rol No 3353-4-2008, de 24 de febrero de 2009, confirmada por la Corte de Apelaciones de San Miguel, rol № 301-2009, de 11 de mayo de 2009.

Sernac y Perona Valenzuela con Supermercado San Bernardo Ltda. (2009): Corte de Apelaciones de San Miguel, rol No 300-2009, de 17 de junio de 2009, que confirma $2^{\circ}$ Juzgado de Policía Local de San Bernardo, rol № 7827-4-2008, de 23 de febrero de 2009.

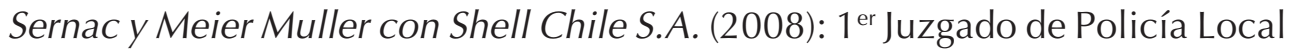
de Providencia, rol No 3305-2-2007, de 9 de enero de 2008, confirmada por la Corte de Apelaciones de Santiago, rol № 1800-2008, de 18 de junio de 2008.

Gutiérrez con Homecenter (2008): 1 ${ }^{\text {er }}$ Juzgado de Policía Local de Viña del Mar, rol No 8306-2007, de 25 de febrero de 2008.

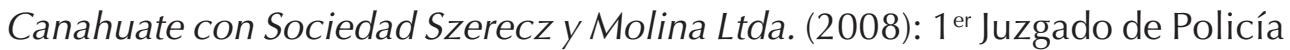
Local de Talcahuano, rol № 5834-2007, de 26 de septiembre de 2008.

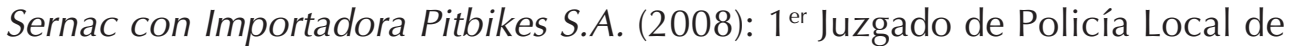
Las Condes, rol No 83989-3-08, de 9 de diciembre de 2008.

Sernac con Comercializadora S.A. (2008): $2^{\circ}$ Juzgado de Policía Local de Puente Alto, rol No 46157-2-2007, de 15 de abril de 2008.

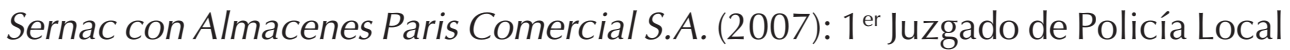
de Santiago, rol No 1390-2006, de 18 de abril de 2007, confirmada por la Corte de Apelaciones de Santiago, rol № 3039-2007, de 4 de julio de 2007. 
Sepúlveda con Café Astoria Fucs y Compañía Limitada (2007): Corte de Apelaciones de Concepción, rol № 500-2005, de 8 de noviembre de 2007.

Sernac con Compañía de Telecomunicaciones de Chile (2007): $1^{\text {er } J u z g a d o ~}$ de Policía Local de Pudahuel, rol № 5278-2006, de 28 de diciembre de 2007, confirmada en este punto por la Corte de Apelaciones de Santiago, rol No 904-2008, de 19 de marzo de 2008.

Sernac y Andrade con Embotelladora Unidas S.A. (2007): Juzgado de Policía Local de Renca, rol No 33862-1-2002, de 28 de marzo de 2007, confirmada por la Corte de Apelaciones de Santiago, rol No 6615-2007, de 9 de enero de 2008.

Sernac y Romero Alarcón con Cencosud Supermercados S.A. (2007): $3^{\text {er Juzgado }}$ de Policía Local de Maipú, rol № 1004-2005, de 31 de diciembre de 2007, confirmada por la Corte de Apelaciones de Santiago, rol № 1724-2008, de 18 de junio de 2008.

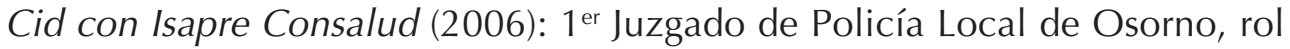
$\mathrm{N}^{\circ}$ 259-2005, confirmada por la Corte de Apelaciones de Valdivia, rol $\mathrm{N}^{\mathrm{o}}$ 125-2006, de 5 de mayo de 2006.

Sernac y Negrete Toro con Derco Autos S.A. (2006): Juzgado de Policía Local de Quilicura, rol No 33622-2006, de 27 de octubre de 2006, confirmada por la Corte de Apelaciones de Santiago, rol № 6923-2006, de 11 de abril de 2007.

Torrealba Aguilera con Curifort (2006): Corte de Apelaciones de Rancagua, rol № 29-2006, de 2 de octubre de 2006, en relación con rol № 352063-2005

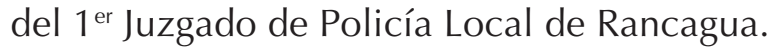

Sernac con Davis Autos S.A. (2006): $4^{\circ}$ Juzgado de Policía Local de Santiago, rol № 79-6-06, de 14 de julio de 2006.

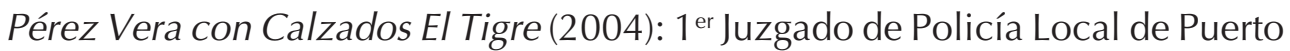
Montt, rol No 2.078-2004, de 26 de julio de 2004. 
